\author{
Subjective Arousal and Perceived Control Clarify Heterogeneity \\ in Inflammatory and Affective Outcomes
}

\author{
Merage Ghane $e_{1,2}$ \\ Holly Sullivan-Toole 1,3 \\ Amanda C. DelGiacco $2^{*}, 4 * *$ \\ John A. Richey 1
}

Author Note

${ }_{1}$ Virginia Tech, Department of Psychology, Clinical Science Program, Blacksburg, VA, USA

2 National Institutes of Mental Health, Intramural Research Training Program, Bethesda, MD, USA (Prior address)*

${ }_{3}$ Graduate Program in Translational Biology, Medicine, and Health, Virginia Tech, Blacksburg, VA, 24061, United States

${ }_{4}$ Oregon Health and Sciences University School of Medicine, Clinical Psychology Program, Portland, OR, USA (Present address)**

* Corresponding Author: Merage Ghane, M.A., mghane@,vt.edu Building 10, Room 4C207

10 Center Dr. MSC 1366

Bethesda, MD 20892-1366

**Word Count including headers: 7,866

Declarations of interest: none

Funding: M.G. is currently and A.C.D was formerly (at the start of the project) supported by the Intramural Research Program of the NIMH (ZIAMH002918) 


\begin{abstract}
Overactivation of proinflammatory pathways in response to stress may play an important role in the pathophysiology of psychiatric disorders such as major depressive disorder. Autonomic arousal in response to chronic stress has been mechanistically linked to the activation of proinflammatory pathways. However, not all individuals who experience chronic stress or increased inflammation develop pathological elevations in symptoms of mood and anxiety disorders. This heterogeneity poses a challenge in using inflammation as a marker of individual risk or vulnerability for related psychiatric conditions. Rodent models of pathological stress suggest that the outcomes of chronic stress may largely depend on individual differences in perceived control. In the current study, we used this theoretical framework to disambiguate the influence of autonomic arousal and perceived control on inflammatory and psychological outcomes in a large sample of adults from the Midlife in the United States dataset (wave 2; MIDUS-2) (Final N=1030), and further replicated our approach in a second (MIDUS-Refresher) cohort (Final $\mathrm{N}=728$ ). Using k-means clustering we created subgroups systematically differing in subjective arousal (high/low) and perceived control (low/high) and compared these subgroups on inflammatory markers and psychological outcomes. Overall results showed that high subjective arousal uniquely and reliably predicted higher levels of Interleukin-6, C-Reactive Protein, and Fibrinogen. However, domain specific heterogeneity in pathological and adaptive affective outcomes, depended on both subjective arousal and perceived control. These results further extend and expand upon basic work in rodent models of stressor controllability and illustrate a useful way to probe mechanistic phenotypes in humans.
\end{abstract}


Keywords: Interleukin-6, Perceived Control, Subjective Arousal, Stress, k-means clustering, CReactive Protein, Psychopathology, Depression, Anxiety, Anhedonia 


\section{Subjective Arousal and Perceived Control Clarify Heterogeneity in Inflammatory and Affective Outcomes}

\section{Introduction}

Substantial prior work has established that both physical and psychological stress activate innate immune responses including systemic inflammation (Glaser \& Kiecolt-Glaser, 2005; Simons, et al., 2017; Steptoe, Hamer \& Chida, 2007). When chronic, both stress and inflammation are further linked with unfavorable medical consequences such as immune suppression, insulin resistance, and poor cardiovascular health (Taylor, 2010; Koolhaas et al., 2011). Additionally, there is increasing support for the idea that inflammatory markers such as C-reactive protein (CRP) and interleukin (IL)-6 among others, may relate to the pathophysiology of several psychiatric conditions, including mood and anxiety disorders (Howren et al., 2009; O’Donovan et al., 2016; Felger et al., 2013; Won et al., 2016; Miller \& Raison, 2016). Although not all individuals with these psychiatric conditions demonstrate elevations in pro-inflammatory markers, those who do report higher rates of co-occurring chronic medical conditions and are less responsive to first-line treatments for mood and anxiety-related symptoms (Michopoulos et al., 2015; Miller et al., 2013; Miller \& Raison, 2015). In particular, a notable link has been established between concentrations of circulating pro-inflammatory markers and symptoms of anhedonia (i.e. loss of interest (amotivation) and/or pleasure (low positive affect)) (Chue \& Lalonde, 2014; Craske, Meuret, Ritz, Treanor \& Dour, 2016; Dunn, 2012). One proposed mechanism by which stress triggers inflammation and associated pathological outcomes is through activation and subsequent dysregulation of the sympathetic nervous system (SNS) (Won and Kim, 2016; Jänig, 2014; Pongratz \& Straub, 2014; Chobanyan-Jürgens \& Jordan, 2015; Acabchuk et al., 2017; Glaser \& Kiecolt-Glaser, 2005). However, recent animal models have proposed that SNS activation (hereafter autonomic arousal) alone cannot distinguish between adaptive versus maladaptive physiological responses to stress, suggesting other factors affect the pathway from stress to specific inflammatory and affective outcomes. 
Heterogeneity in stress-related outcomes has been documented across a range of experimental models and species. For example, only a subset of rodents and humans who experience chronic stress and/or prolonged inflammation display unfavorable affective and behavioral outcomes such as social defeat, learned helplessness, and mood/anxiety disorders (Hodes et al., 2014; Ambrée et al., 2018; Kunz-Ebrecht, Mohamed-Ali et al., 2003; Pfau \& Russo, 2014). Conversely physiological stress responses that reflect autonomic arousal, may also result in adaptive outcomes for select individuals (i.e. resiliency) or in contexts other than stress (in the negative sense of the word), such as exercise. Autonomic arousal is known to increase the production of cytokines such as IL-6, and yet elevations in this marker can have both pro- and antiinflammatory effects depending on its specific mechanism of action (Koopman et al., 2011; Scheller et al., 2011). Increased autonomic arousal also promotes activation of adaptive immune cells (Kenney \& Ganta, 2014), which are believed to prepare and protect against comparable stress in the future (Lewitus \& Schwartz, 2009). These cells can also trigger changes in metabolic, cardiovascular, and neural systems necessary for supporting and sustaining adaptive behavioral responses during periods of high stress (McEwen \& Wingfield, 2003; de Kloet, Joels, \& Holsboer, 2005), but may not necessarily result in pathological outcomes post-stress. These ideas collectively suggest that autonomic arousal alone may not be enough to sensitively predict pathological inflammatory or affective outcomes, and that additional environmental or internal (cognitive) factors may contribute to the observed variability.

Models of pathological stress in rodents have identified the (lack of) stressor controllability, or individual differences in detecting controllability, as critical in differentiating between maladaptive and adaptive outcomes of stress on immune and behavioral responses (Koolhaas et al., 2011). This suggests that perceptions of control may play a similar role in unfavorable inflammatory and affective responses even under similar levels of subjective SNSrelated arousal in humans. Despite its well-established role in the promotion of mental and physical health, the mechanisms by which perceived control putatively improves health remain largely unknown. Recent theoretical models of stress have identified perceived control as a potential 
moderator of autonomic responses to environmental challenges, and subsequent pathology (Dickerson \& Kemeny, 2004; Koolhaas et al., 2011). For example, in rodents, control over stressors reduces the duration, although not the magnitude of SNS and hypothalamic pituitary adrenal-axis response to environmental stressors (Koolhaas et al., 2011), minimizing the chronicity of heightened arousal, and associated immune and metabolic costs. At the biological level, controllable versus uncontrollable shock leads to greater accumulation of adaptive immune cells during injury or pathogen exposure (Ciavarra et al., 2018). These cells increase the expression of brain-derived neurotrophic factors (BDNF), which may protect against inflammation-related excitotoxicity (Yang, Shirayama, Zhang, Ren, \& Hashimoto, 2015; Kerschensteiner et al., 1999), and reduce susceptibility to depressive behaviors (Banasr, Dwyer, \& Duman, 2011). In addition to its influence on the duration of autonomic responses to acute stress and promotion of adaptive immune responses, perceived control also influences behavioral and affective outcomes. Stressrelated SNS activation is typically associated with increases in negative mood and feelings of anxiety, while higher perceived control is associated with increased positive affect (Bogdan, Pringle, Goetz \& Pizzagalli, 2012; MacAulay, McGovern \& Cohen, 2014). It has been further suggested that higher perceived control may buffer against the negative effects of stress through changes in how individuals cope with aversive emotional or physiological states (Bhanji, Kim \& Delgado, 2016; Elliot, et al., 2018). For example, in both rodents (Foa et al., 1992) and humans (Dijkstra \& Homan, 2016; Fontain, Manstead, \& Wagner, 1993), higher perceived control results in greater active (goal-oriented; problem-focused) and less passive (reactive; emotion-focused) coping in the context of stress, the former of which has been associated with more favorable longterm health, social, and emotional outcomes.

Together, these findings suggest that both perceived control and autonomic arousal influence inflammatory, behavioral, and emotional outcomes but through potentially distinct mechanisms. In humans, objective (e.g skin conductance, heart rate, heart rate variability, cortisol) and subjective (e.g. self-reported somatic symptoms such as a racing heart, shakiness, shortness of breath, dry mouth, etc.) measures of autonomic arousal and perceived control have been separately 
studied in the context of health outcomes, and when studied together, low perceived control is often collinear with high arousal (and vice versa) (e.g. Bandura et al., 1987;. However, little is known about their combined influence on individual differences in inflammatory and affective functioning in humans. Addressing this gap provides an opportunity to more precisely identify individuals at-risk for undesirable long-term mental health outcomes of pro-inflammatory responses to stress, and who might benefit from different first-line treatment considerations. In the current study we used two large samples of data $(\mathrm{N}=1030$ and $\mathrm{N}=728)$ from the Midlife in the United States (MIDUS) study to create subgroups ( $k$ means clustering) that differed systematically in 1) subjective autonomic arousal and 2) perceived control. We then used these subgroups to systematically probe the unique and combined contributions of arousal and perceived control on baseline proinflammatory marker levels and affective symptoms. In light of evidence suggesting that measures of autonomic arousal predict greater proinflammatory activity, we hypothesized that high (relative to low) levels of subjective arousal would predict elevated concentrations of proinflammatory markers (e.g. IL-6, CRP, etc.). We also tested whether perceived control independently or through interactions with arousal further predicted additional variance in proinflammatory marker levels. Along similar lines, we predicted that individuals reporting high arousal would also report poorer affective outcomes (relative to the total sample mean and to those reporting low arousal) across multiple domains (depressive distress, anxious distress, loss of interest, and positive affect). Consistent with prevailing models of pathological stress in rodents (Koolhaas et al., 2011), we predicted the negative effects of high arousal would be amplified (relative to the total sample mean and to those reporting low arousal) when perceived control was also low. To link findings to pathology (above and beyond symptoms), we conducted several exploratory analyses to examine whether subgroups differed on risk for psychiatric pathology.

\section{Methods}

\subsection{Data}

We used publicly available data from the survey and biomarker sessions of the MIDUS study, a national multi-site longitudinal study of health and well-being (https://midus.wisc.edu/; 
Radler, 2014 ). The data reported here were drawn from the first follow-up of the original sample (MIDUS-2), which was collected between 2004 and 2009. We additionally used data from a second separate cohort of participants that paralleled the design and protocol of the MIDUS-2 dataset (MIDUS Refresher; MIDUS-R). These data were collected between 2011 and 2016. We conducted the analyses separately in each dataset in order to probe the replicability of results across samples. We included participants who had complete data for all primary self-report measures and inflammatory markers of interest. Participants are described separately for each dataset below. Supplementary Table 1 summarizes which session (survey or biomarker) each variable was collected during.

Of the 1255 individuals who participated in the MIDUS-2 biomarker project, 1054 had data from the survey session as well. Of these 1054 participants, $1030($ Female $=560$, Male $=470)$ had complete data for all measures of interest. Participants in this final subsample were between the ages of 35 and $86\left(\mathrm{M}_{\mathrm{Age}}=57.96 ; \mathrm{SEM}_{\mathrm{Age}}=.360\right)$. On average, data for the biomarker session was collected 25.85 months after survey session data collection $\left(\mathrm{SEM}_{\mathrm{Lag}}=.460 ;\right.$ Range $_{\mathrm{Lag}}=0-62$ months) (Table 2 in Results). Of the 863 individuals who participated in the MIDUS-R biomarker project, 746 had data from the survey session as well. Of these 746 participants, 728 (Female $=361$, Male =367) had complete data for all primary measures of interest. Participants in this final subsample were between the ages of 26 and $78\left(\mathrm{M}_{\mathrm{Age}}=53.53 ; \mathrm{SEM}_{\mathrm{Age}}=.507\right)$. On average, data for the biomarker session was collected 21.17 months after survey session data collection $\left(\mathrm{SEM}_{\mathrm{Lag}}=.327 ;\right.$ Range $_{\mathrm{Lag}}=6-52$ months) (Table 2). See Table 2 in results for further sample characteristics and between sample differences on variables of interest.

\subsection{Measures}

\subsubsection{Primary Self-Report Measures}

Mood and Anxiety Symptom Questionnaire (MASQ). Participants completed a 62-item version of the MASQ, which is a dimensional measure of affective symptoms based on a tripartite model of anxiety and depression (Clark \& Watson, 1991). This measure includes five subscales: depressive distress, anxious distress, loss of interest, high positive affect, and anxious arousal. 
Participants were asked to rate how much they experienced each item during the past week on a Likert scale ranging from 1 (not at all) to 5 (extremely). The anxious arousal (AA) subscale measures intensity of self-reported physiological symptoms associated with autonomic arousal (e.g. "was trembling or shaking”, "felt dizzy or lightheaded" (Clark \& Watson, 1991). We used the sum of items on the AA subscale as our index of stress-related autonomic arousal (Larson, Nischke, \& Davidson, 2007); symptoms from this scale index physiological burden more generally, and do not refer to the valence (positive/negative), or effect (adaptive/maladaptive) of these symptoms (Larson et al., 2007). Cronbach's alpha for this scale was acceptable in both samples (MIDUS-2 $\alpha=.777$; MIDUS-R $\alpha=.761$ ).

Items from the depressive distress (DD) subscale assess symptoms linked to depression and low mood (e.g. "felt sad", "felt like a failure") (MIDUS-2 Chronbach's $\alpha=.903$; MIDUS-R Cronbach's $\alpha=.873$ ). The anxious distress (AD) subscale measures discomfort typically associated with anxiety (e.g. "felt nervous", "felt uneasy") (MIDUS-2 Chronbach's $\alpha=.790$; MIDUS-R Cronbach's $\alpha=.799$ ). Loss of interest (LI) measures non-specific lack of motivation typical in patients with depression (e.g. "felt really slowed down", "felt nothing fun/interesting to do") (MIDUS-2 Chronbach's $\alpha=.813$; MIDUS-R Cronbach's $\alpha=.797$ ). Finally, the high positive affect subscale (PA) includes items associated with the experience of positive emotions and optimism (e.g. "Felt really happy", "Looked forward with enjoyment”) (MIDUS-2 Chronbach's $\alpha=.93$; MIDUS-R Cronbach's $\alpha=.93$ ). We used the standardized sum of items on the MASQ-DD, MASQ-AD, MASQ-LI, and MASQ-PA subscales as our measure of affective outcomes in various subdomains of positive and negative affect. Higher scores in DD, AD, and LI and lower scores in PA correspond with greater symptom severity.

Sense of Control Scale (SCS). The SCS is a 12-item measure with two subscales (personal mastery and perceived constraints), developed by Lachman and Weaver (1998). Personal mastery refers to self-efficacy/effectiveness in reaching goals (e.g. "I can do just about anything I really set my mind to"). The perceived constraints subscale measures the extent to which factors beyond one's control contribute to experienced outcomes (e.g. "What happens in my life is often beyond 
my control"). The scale requires participants to rate items on a Likert scale which ranged from 1 (Strongly Agree) to 7 (Strongly disagree). Personal Mastery items were reverse scored so that higher total scores reflected greater perceptions of control. Composite scores, created by calculating the mean of all 12 items, were used for all analyses. Mean Cronbach's alpha across the two subscales was good at $\alpha=.79$ in the MIDUS- 2 sample and $\alpha=.81$ in the MIDUS-R sample.

\subsubsection{Inflammatory Markers}

We included inflammation-related markers that overlapped both in their method of measurement and type for both MIDUS-2 and MIDUS-R samples. Thus, the following inflammation-related markers were used as outcome measures: IL-6, serum IL-6 soluble receptors (IL-6SR), CRP, Fibrinogen (FIB), E-Selectin (ELAM-1), and Intercellular Adhesion Molecule 1 (ICAM-1). These markers are linked to higher levels of inflammation, however IL-6 and CRP have also been reliably associated with affective outcomes (See Supplementary Material for further details on measurement, functional role). Both Kolmogorov-Smirnov and Shapiro-Wilk tests of normality suggested significant deviations from the normal distribution for all markers (all positively skewed; all ps <.001). Qualitative inspection of normal and detrended Q-Q plots, and stem-and-leaf plots provided evidence for considerable positive skew for IL-6, CRP, and ICAM1, which were thus natural $\log$ transformed, consistent with common practice. Post-transformation, plots were visually inspected to ensure normal distribution. All measures were standardized separately in each dataset based on the population mean $(z)$ for ease of visualization and due to differing units of measurement.

\subsection{Data Analysis}

\subsubsection{Subgrouping Using K-Means Clustering}

K-means clustering is an unsupervised machine learning algorithm for separating data (in this case individual participants) into $k$ number of clusters (or groups) given a set of data points (e.g. behavioral, self-report, physiological measures). The number of groups that are specified $a$ priori may be for a combination of both theoretical and data-driven reasons (Kaufman \& Rousseeuw, 1990). Well-defined clusters are those that generally have high intra-cluster similarity 
(low within cluster variance) and low inter-cluster similarity (high between-cluster variance). All clustering and statistical tests were conducted in SPSS (IBM SPSS Statistics Subscription, Build 1.0.0.1118, 64-bit edition, IBM Corp, 2018). We evaluated clustering solutions using the silhouette function in MATLAB (Mathworks, R2016b). Clusters were created using the anxious arousal subscale from the MASQ (hereafter AA) as a measure of SNS-related arousal and the composite score from the sense of control scale (hereafter CNTL) as a measure of perceived control to systematically test the unique and shared contributions of symptoms of SNS-related arousal and perceived control, respectively, on inflammatory and affective outcomes. Our goal was to create four subgroups, two that were homogeneous in their AA symptoms but differed in CNTL and two others that were similar in CNTL and differed in AA. Due to the skewed distribution of data for both AA (positive skew) and CNTL scales (negative skew), we used k-means in favor of methods of splitting data with measures of central tendency. Additionally, no formal clinically relevant cutoffs have been defined in the literature for these measures, thus we opted for a partially datadriven method. This also ensured that results are agnostic with respect to diagnostic categorization, focusing instead on naturally occurring variability in the dimensions of interest. Due to differences in measurement scales, we standardized AA and CNTL scores $(\mathrm{z})$ to each sample mean prior to clustering. There was a moderate but significant negative correlation between AA and CNTL in the MIDUS-2 (rho $=-.277, \mathrm{p}<.001)$ and MIDUS-R samples $($ rho $=-.294, \mathrm{p}<.001)$.

To create subgroups based on AA, we used k-means clustering with squared Euclidean distance as our distance metric, setting the number of iterations to $\leq 100$ (or until change in centroids converged to zero). To maximize the between group differences on this variable and create high and low AA subgroups, we opted to define $\mathrm{k}=2$ in our initial model. We evaluated the quality of our clusters using mean silhouette values for $\mathrm{k}$ ranging from 2-10 (Kaufman and Rousseeuw, 1990). Silhouette values above 0.50 suggest good cohesion within clusters, relative to separation between clusters (Kaufman \& Rousseeuw, 1990). All silhouette values for k ranging from 2-10 were about .50 , and the solution for $\mathrm{k}=2$ was the most optimal (highest silhouette value; Supplementary Figures 1A-D). As such, we moved forward with our choice of $k=2$ to maintain 
parsimony and ease of interpretation. We repeated the same procedure using CNTL scores to create $\mathrm{k}=2$ clusters that differed maximally on perceived control (high and low).

The overlap of the AA and CNTL clusters (their interaction) defined the four final subgroups (high AA/low CNTL, high AA/high CNTL, low AA/low CTNL, and low AA/high CNTL). We opted for this method over starting with $\mathrm{k}=4$ along both AA and CNTL dimensions to ensure that subgroups were defined along one dimension but were allowed to differ on the other and vice versa. Using the k-means algorithm along both AA and CNTL dimensions would have grouped individuals based on the assumption that subgroups are to be maximally dissimilar on both of these dimensions (Kaufman \& Rousseeuw, 1990). We checked the quality of our subgroup solution by testing whether mean silhouette values were above the 0.50 criterion. Mean silhouette coefficients were 0.60 for the MIDUS-2 sample and 0.62 for the MIDUS-R sample, suggesting that our four subgroups were sufficiently similar within combined AA/CNTL subgroups and dissimilar between subgroups. We denote these subgroups as AA+ or AA- (for high and low AA) and CNTL+ or CNTL- (for high and low perceived CNTL).

We tested for differences between resulting subgroups on subject characteristics (age, BMI, income, race, Lag between sessions, and gender; See Results) as well as AA and CNTL scores (See Figure 1). For differences in proportions we used the chi-square test and for continuous measures we used a one-way ANOVA. Post-hoc pairwise tests were corrected for multiple comparisons using the Bonferroni method. When assumptions of homogeneity of variance were not met, we report Welch's F with adjusted degrees of freedom (post-hoc pairwise tests corrected for multiple comparisons using Games-Howell). 

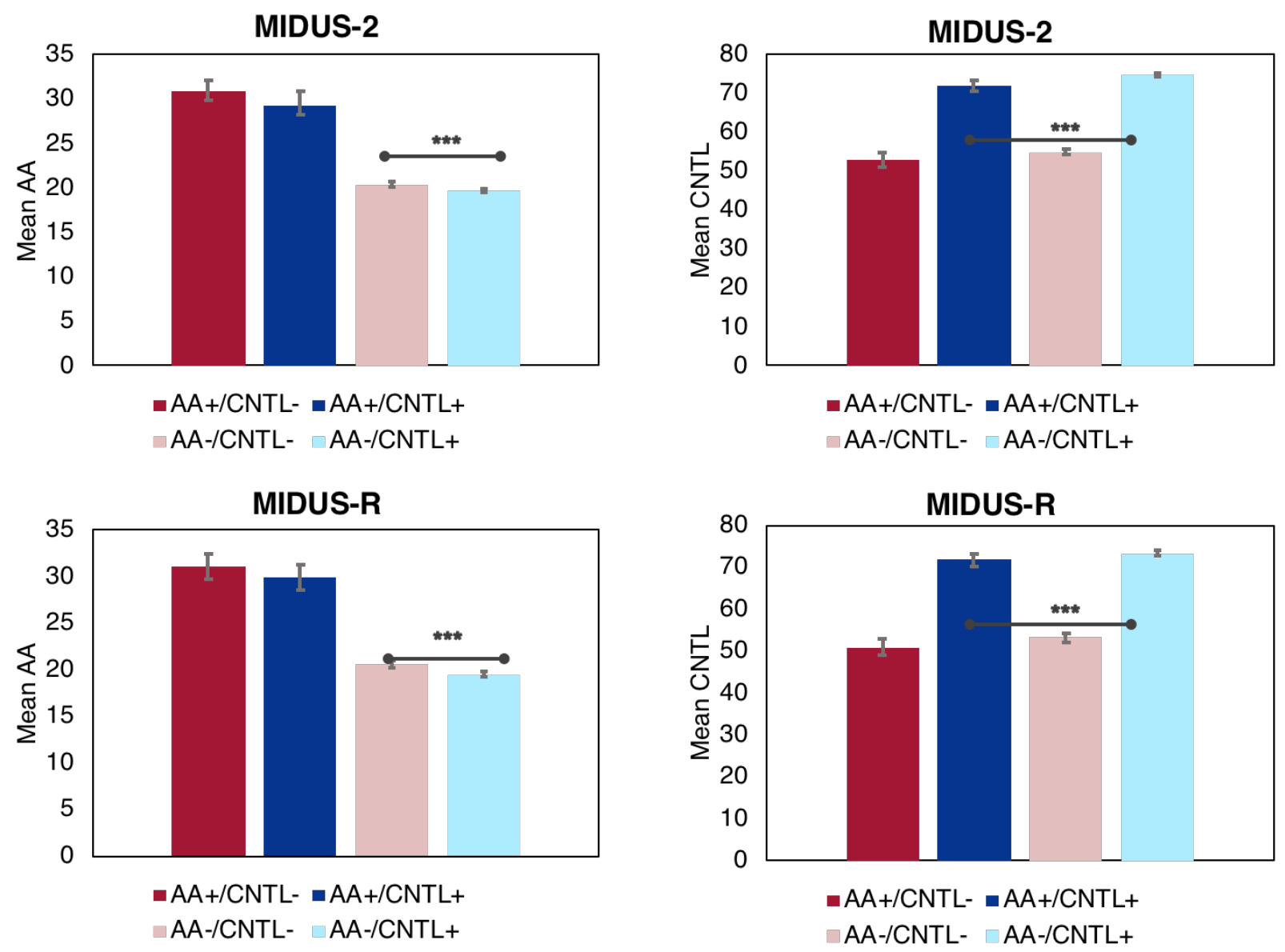

Figure 1. Error bars are Bootstrapped (1000 samples) $95 \%$ confidence intervals. All significant pairwise differences are at Games-Howell corrected p-values $<.001$. Top row depicts mean raw AA and CNTL scores (left to right) per subgroup for the MIDUS-2 sample, while the bottom row depicts scores for MIDUS-R sample.

As expected, both AA+ subgroups demonstrated significantly greater AA scores than the AA- subgroups (error bars do not overlap) and were not significantly different from one another (Games-Howell corrected; MIDUS-2 $\mathrm{p}=.223$, MIDUS-R $\mathrm{p}=.612$ ). Likewise, both CNTLsubgroups demonstrated significantly lower CNTL scores than both CNTL+ subgroups, and were not significantly different from each other (Games-Howell corrected; MIDUS-2 $p=.229$, MIDUS$\mathrm{R} \mathrm{p}=.211)$. Individuals in the AA-/CNTL+ subgroup reported lower AA compared to those in the AA-/CNTL- subgroup. Those in the AA+/CNTL+ subgroup reported lower CNTL than those in the AA-/CNTL+ subgroup. Results were the same between the two samples, which suggests that the clustering method and subgrouping strategy produced phenotypically reliable groupings across AA and CNTL dimensions in both cohorts. 


\subsubsection{Statistical Analysis}

To test hypotheses related to associations between perceived control and self-reported arousal with individual differences in pro-inflammatory activity and affective outcomes, separate univariate GLMs (Type III Sums of Squares) probed main effects and interactions of AA and CNTL factors on inflammatory marker levels and affective domains. We initially planned to include age (Z), sex, BMI (Z), and lag $(Z)$ in all primary models. Based on findings suggesting a causal relationship between metabolic syndrome and inflammation (Ellulu et al., 2017; ), we did not include BMI as a covariate in the inflammatory markers model. However, due to differences between subgroups on several of these variables (see results section), we elected to run a more basic primary model that included only covariates that did not differ between subgroups. This choice was due to evidence suggesting that between group differences on within group covariates can lead to overcorrecting, biasing, or incorrectly estimating model parameters and between group effects (Schneider, Avivi-Reich, \& Mozuraitis, 2015). Instead, we followed up on primary models with secondary models to test the sensitivity of our initial effect after including covariates and their subgroup interactions (Miller \& Chapman, 2001). The results of these secondary models are presented in the supplemental materials. For significant univariate effects, if assumptions were met for parametric statistical tests, we used post-hoc pairwise mean difference tests to probe these effects (Bonferroni corrected). When assumptions were not met, we used non-parametric tests (Kruskal-Wallis and Dunn's Bonferroni correction for post-hoc pairwise tests). To determine how

each subgroup compared to the entire sample, we compared estimated marginal means for all subgroups against the grand mean of the sample.

\subsubsection{Exploratory Analyses}

To explore the association between the characteristics of identified subgroups and mental and physical health conditions, we followed up our main analyses with several exploratory analyses using data available on the prevalence of these outcomes in each sample. We used data on whether participants met clinical criteria for depression, panic disorder, and generalized anxiety (yes/no) based on responses to DSM-IV symptom cluster questions gathered via phone interview. 
We also examined self-reported responses (yes/no) to the question "Have you had depression, anxiety, or any other emotional disorder over the past 12 months?" (survey session; 0\% missing in MIDUS-2, 1.5\% missing in MIDUS-R), and "Have you ever had depression?" (biomarkers session; .002\% missing in MIDUS-2, 0\% missing in MIDUS-R). For the latter question, if a participant responded "Borderline" or "Unsure", we took a conservative approach and re-coded these responses as "No". Chi-squared tests were used to determine whether there was a significant effect of subgroup on these dependent variables. We also computed a prevalence ratio (PR) by dividing the point prevalence (of "yes" responses; $(Y)$ ) for each subgroup $(G)$ and each item, by the point prevalence across the entire sample (S) for that item. This value allows us to quantify the degree to which each subgroup disease burden differs from what is expected from the total sample, and the direction of this difference. Given that the prevalence of several psychiatric disorders (e.g. Depression) may differ across sexes, we computed PRs separately for males and females. Values less than one suggest a reduced prevalence, those equal to one suggest prevalence is similar to sample prevalence, and values greater than one suggest a greater prevalence relative to the total sample [Eq. 1].

[Eq. 1]

$$
P R=\frac{P(Y \mid G)}{P(Y \mid S)}
$$

\section{Results}

\subsection{Participant Characteristics}

\subsubsection{Between Sample Differences in Participant Characteristics}

MIDUS-2 and MIDUS-R dataset participant characteristics are summarized in Table 1. Individuals in the MIDUS-2 sample were significantly more likely to be female, white, older (Hedges' $\mathrm{g}=.35$ ), have slightly lower BMI (Hedges' $\mathrm{g}=.11$ ), and have greater lag between questionnaire and biomarkers sessions when compared to the MIDUS-2 sample. In the MIDUS-R

sample, there was a significantly greater proportion of individuals who identified as primarily Black/African American (\%MIDUS2 = 2.5\%; \%MIDUSR = 7.1\%; $\mathrm{z}=-1.98, \mathrm{p}=.048)$, Asian 
$(\%$ MIDUS2 $=.2 \% ; \%$ MIDUSR $=1.5 \% ; \mathrm{z}=-2.83, \mathrm{p}=.005)$, and Other $(\%$ MIDUS2 $=2.7 \%$;

$\%$ MIDUSR $=7.6 \% ; \mathrm{z}=-4.71, \mathrm{p}<.001)$ when compared to the MIDUS-2 sample. For further results related to between sample differences in participant characteristics, see supplemental material.

Table 1. MIDUS-2 and MIDUS-R Differences in Sample Characteristics

\begin{tabular}{|c|c|c|c|}
\hline Measure & $\begin{array}{l}\text { MIDUS-2 } \\
(\mathrm{N}=1030)\end{array}$ & $\begin{array}{l}\text { MIDUS-R } \\
(\mathrm{N}=728)\end{array}$ & $\begin{array}{c}\text { Between Sample Statistic } \\
\text { (df) } \\
\text { sig. }\end{array}$ \\
\hline $\begin{array}{c}\text { Sex } \\
\% \text { Female }\end{array}$ & $54.4 \%$ & $49.6 \%$ & $\begin{array}{l}\chi^{2}(1)=3.91 \\
\mathrm{p}=.048\end{array}$ \\
\hline $\begin{array}{c}\text { Primary Identified Race } \\
\% \text { White }\end{array}$ & $92.8 \%$ & $80.6 \%$ & $\begin{array}{c}\chi^{2}(7)=62.91 \\
\mathrm{p}<.001\end{array}$ \\
\hline $\begin{array}{l}\text { Ever Depressed or } \\
\text { Anxious } \\
\% \text { Yes last } 12 \text { mo. }\end{array}$ & $19.2 \%$ & $19.7 \%$ & $\begin{array}{c}\chi^{2}(1)=.053 \\
\mathrm{p}=.818\end{array}$ \\
\hline $\begin{array}{c}\text { Age } \\
\text { Mean (SD) }\end{array}$ & $\begin{array}{l}57.96 \\
(11.57)\end{array}$ & $\begin{array}{c}53.53 \\
(13.68)\end{array}$ & $\begin{array}{c}\mathrm{t}(1395.90)=7.12 \\
\mathrm{p}<.001\end{array}$ \\
\hline $\begin{array}{c}\text { BMI } \\
\text { Mean (SD) }\end{array}$ & $\begin{array}{l}29.10 \\
(5.93)\end{array}$ & $\begin{array}{l}29.84 \\
(7.24)\end{array}$ & $\begin{array}{c}\mathrm{t}(1363.17)=-2.27 \\
\mathrm{p}=.023\end{array}$ \\
\hline $\begin{array}{l}\text { Lag Between Sessions } \\
\text { Mean months (SD) }\end{array}$ & $\begin{array}{c}27.79 \\
(14.77)\end{array}$ & $\begin{array}{l}22.46 \\
(8.92)\end{array}$ & $\begin{array}{c}\mathrm{t}(1717.64)=9.41 \\
\mathrm{p}<.001\end{array}$ \\
\hline $\begin{array}{l}\text { Total HH Income } \\
\text { Mean USD (SD) }\end{array}$ & $\begin{array}{l}77,413.40 \\
(60,700.46)\end{array}$ & $\begin{array}{c}90,939.99 \\
(65,662.23)\end{array}$ & $\begin{array}{c}\mathrm{t}(1435.59)=-4.325 \\
\mathrm{p}<.001\end{array}$ \\
\hline
\end{tabular}

Based on Levene's test, assumptions for homogeneity of variance were not met for any of the continuous variables. As such, corrected degrees of freedom were used for reported t-tests.

\subsubsection{Between Subgroup Differences in Participant Characteristics}

The proportion of participants who fell into each subgroup is summarized in Figure 2. Despite clustering each sample separately, there were no significant differences between MIDUS-2 and MIDUS-R in the proportion of individuals who fell into each respective subgroup $\left(\chi^{2}=.354, \mathrm{p}=\right.$ 
.950). In order to have a sufficient number of individuals within each cell for race distribution comparisons between subgroups, we reduced the granularity of the race category to 4 (instead of 7). These categories were recoded to be White, Black and/or African American, Other (non-white or non-black; included Asian, Native American/Alaska Native/Aleutian Islander/Eskimo, Asian, Native Hawaiian/Pacific Islander, or indicated as other), and Unknown/Refused. The demographic characteristics of each subgroup were compared within each sample (see Table 2 and Table 3 ).
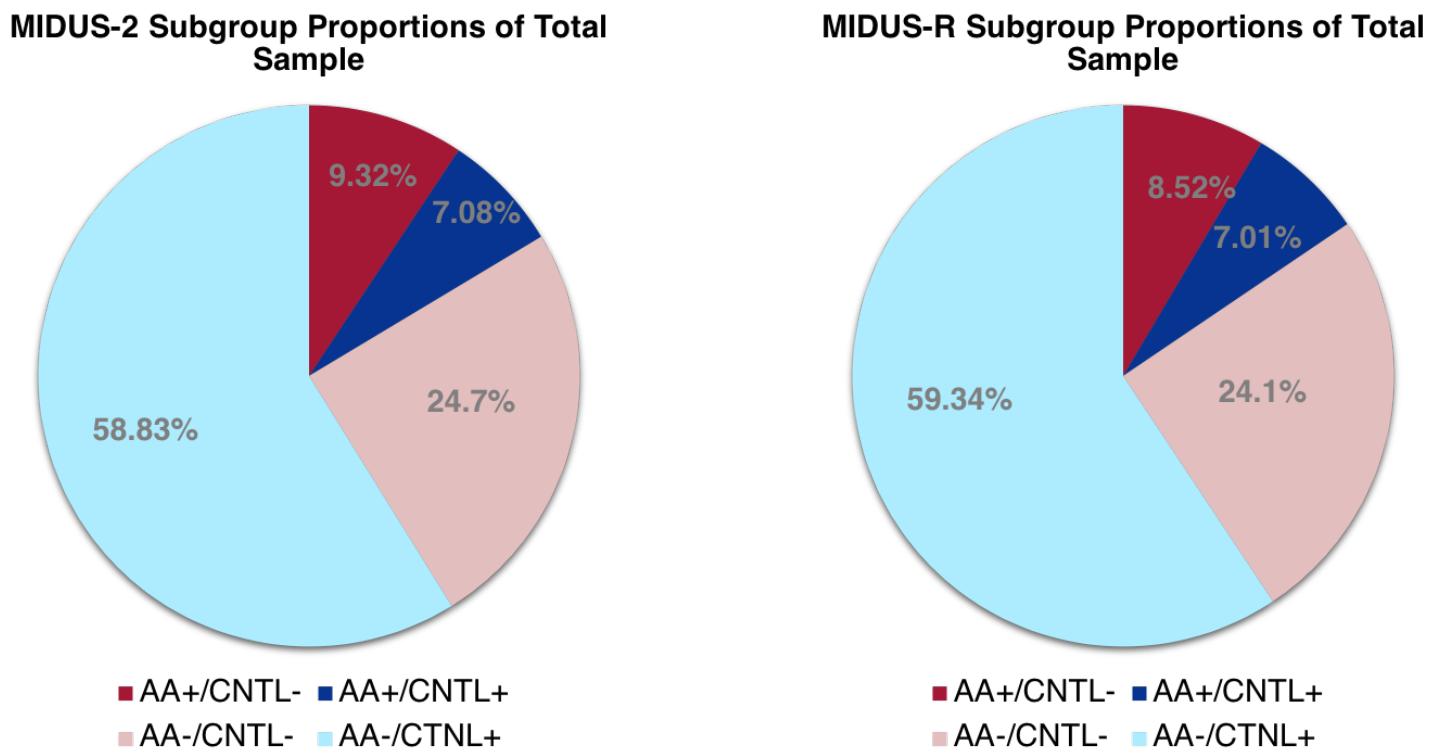

Figure 2. Left. A majority of the MIDUS-2 sample fell into the AA-/CNTL+ subgroup (58.83\%), followed by the AA-/CNTL- (24.7\%), AA+/CNTL- (9.32\%), and AA+/CNTL+ subgroup (7.08\%). Right. Similar proportions were observed in the MIDUS-R sample, with 59.34\% in the AA-/CNTL+ subgroup, 24.14\% in the AA-/CNTL- subgroup, $8.52 \%$ in the $\mathrm{AA}+/ \mathrm{CNTL}-$ subgroup, and $7.01 \%$ in the $\mathrm{AA}+/ \mathrm{CNTL}+$ subgroup.

MIDUS-2. Results revealed a significant effect of gender, age, BMI and income by subgroups in the MIDUS-2 sample (Table 2). Post-hoc tests revealed that there was a significantly higher proportion of females in the AA+/CNTL- subgroup compared to the AA-/CNTL+ subgroup $(\mathrm{z}=$ 2.83, Bonferroni corrected $\mathrm{p}<.05)$. Individuals in the $\mathrm{AA}+/ \mathrm{CNTL}+$ subgroup were significantly older than those in the AA+/CNTL- subgroup (corrected $\mathrm{p}=.03$ ). The AA+/CNTL+ subgroup had higher BMI than both AA- subgroups (Games-Howell corrected ps <.05). Excluding those who had missing data, individuals in the AA-/CNTL+ subgroup reported household incomes that were significantly higher than all other subgroups (Games-Howell corrected ps $<.005$ ). No other 
differences between subgroups were statistically significant after correction for multiple comparisons.

\begin{tabular}{|c|c|c|c|c|c|c|c|}
\hline Measure & Value & $\begin{array}{l}\text { MIDUS-2 } \\
\text { Total } \\
\mathrm{N}=1030\end{array}$ & $\begin{array}{l}\mathrm{AA}+/ \mathrm{CNTL}- \\
\mathrm{n}=96\end{array}$ & $\begin{array}{l}\mathrm{AA}+/ \mathrm{CNTL}+ \\
\mathrm{n}=73\end{array}$ & $\begin{array}{l}\text { AA-/CNTL- } \\
\mathrm{n}=255\end{array}$ & $\begin{array}{l}\text { AA-/CNTL+ } \\
n=606\end{array}$ & $\begin{array}{l}\text { Statistic (df) } \\
\text { sig. }\end{array}$ \\
\hline Sex & $\begin{array}{l}\% \text { Female } \\
{[95 \% \text { C] }}\end{array}$ & $\begin{array}{l}54.4 \% \\
{[51.32-57.39]}\end{array}$ & $\begin{array}{l}66.67 \% \\
{[56.75-75.29]}\end{array}$ & $\begin{array}{l}57.53 \% \\
{[46.10-68.22]}\end{array}$ & $\begin{array}{l}56.47 \% \\
{[50.33-62.42]}\end{array}$ & $\begin{array}{l}51.15 \% \\
{[47.18-55.12]}\end{array}$ & $\begin{array}{l}\chi^{2}(3)=9.12 \\
p=.028\end{array}$ \\
\hline $\begin{array}{l}\text { Primary } \\
\text { Race }\end{array}$ & $\begin{array}{l}\% \text { White } \\
{[95 \% \mathrm{Cl})}\end{array}$ & $\begin{array}{l}92.8 \% \\
{[91.42-95.02]}\end{array}$ & $\begin{array}{l}93.75 \% \\
{[90.63-98.66]}\end{array}$ & $\begin{array}{l}90.41 \% \\
{[84.93-96.49]}\end{array}$ & $\begin{array}{l}92.54 \% \\
{[89.80-95.52]}\end{array}$ & $\begin{array}{l}93.06 \% \\
{[91.42-95.02]}\end{array}$ & $\begin{array}{l}\chi^{2}(18)=19.72 \\
p=.349\end{array}$ \\
\hline \multirow[t]{2}{*}{ Age } & $\begin{array}{l}\text { Mean (SD) } \\
{[95 \% \mathrm{Cl}]}\end{array}$ & $\begin{array}{l}57.96(11.57) \\
{[57.25-58.67]}\end{array}$ & $\begin{array}{l}56.51(11.70) \\
{[54.14-58.88]}\end{array}$ & $\begin{array}{l}61.53(11.56) \\
{[58.84-64.23]}\end{array}$ & $\begin{array}{l}57.82(12.02) \\
{[56.34-59.30]}\end{array}$ & $\begin{array}{l}57.82(11.30) \\
{[56.91-58.72]}\end{array}$ & \multirow[t]{2}{*}{$\begin{array}{l}\mathrm{F}(3,1026)=2.89 \\
\mathrm{p}=.035\end{array}$} \\
\hline & Median & 57.96 & 54.50 & 62.00 & 56.00 & 58.00 & \\
\hline \multirow[t]{2}{*}{ BMI } & $\begin{array}{l}\text { Mean (SD) } \\
{[95 \% \mathrm{Cl}]}\end{array}$ & $\begin{array}{l}29.10(5.93) \\
{[28.74-29.46]}\end{array}$ & $\begin{array}{l}30.58(7.46) \\
{[29.06-32.09]} \\
\end{array}$ & $\begin{array}{l}31.21(6.84) \\
{[29.61-32.80]} \\
\end{array}$ & $\begin{array}{l}28.90(5.70) \\
{[28.20-29.61]}\end{array}$ & $\begin{array}{l}28.69(5.55) \\
{[28.25-29.13]} \\
\end{array}$ & \multirow{2}{*}{$\begin{array}{l}\text { Welch } \\
\mathrm{F}(3,205.73)= \\
4.58 \\
\mathrm{p}=.004\end{array}$} \\
\hline & Median & 28.14 & 29.11 & 30.19 & 28.42 & 27.77 & \\
\hline \multirow[t]{2}{*}{ Lag } & $\begin{array}{l}\text { Mean (SD) } \\
{[95 \% \mathrm{Cl}]}\end{array}$ & $\begin{array}{l}27.79(14.77) \\
{[24.95-26.76]}\end{array}$ & $\begin{array}{l}24.35(13.80) \\
{[21.56-27.15]}\end{array}$ & $\begin{array}{l}26.74(15.16) \\
{[23.30-30.28]}\end{array}$ & $\begin{array}{l}25.77(15.53) \\
{[23.85-27.68]}\end{array}$ & $\begin{array}{l}26.02(14.56) \\
{[24.86-27.18]}\end{array}$ & \multirow[t]{2}{*}{$\begin{array}{l}F(3,1026)=.445 \\
p=.721\end{array}$} \\
\hline & Median & 24.00 & 23.50 & 24.00 & 22.00 & 24.00 & \\
\hline \multirow[t]{2}{*}{$\begin{array}{l}\mathrm{HH} \\
\text { Income } \\
\text { (USD) }\end{array}$} & $\begin{array}{l}\text { Mean (SD) } \\
{[95 \% \mathrm{Cl}]}\end{array}$ & $\begin{array}{l}77,413.40 \\
(60,700.46) \\
{[73,661.67-} \\
81,165.13]\end{array}$ & $\begin{array}{l}60,315.77 \\
(47,870.76) \\
{[50,456.91-} \\
70,174.64]\end{array}$ & $\begin{array}{l}61,601.87 \\
(37,435.30) \\
{[52,675.74-} \\
70,528.00]\end{array}$ & $\begin{array}{l}69,546.70 \\
(57,497.69) \\
{[62,384.54-} \\
76,708.87]\end{array}$ & $\begin{array}{l}85,251.32 \\
(64,652.81) \\
{[80,045.81-} \\
90,456.82]\end{array}$ & \multirow[t]{2}{*}{$\begin{array}{l}\text { Welch } \\
\mathrm{F}(3,236.36)= \\
11.53 \\
\mathrm{p}<.001\end{array}$} \\
\hline & Median & $62,500.00$ & $52,500.00$ & $60,475.00$ & $57,390.00$ & $70,500.00$ & \\
\hline
\end{tabular}

Based on Levene's Test, assumptions for homogeneity of variance were not met for BMI and total HH income. Welch's test of equality of means conducted and asymptotic $\mathrm{F}$ reported for these two variables.

MIDUS-R. There was a significant effect of gender, race, age, BMI, and income by subgroup in the MIDUS-R sample (Table 3). There was a higher proportion of females in the AA+/CNTL+ subgroup compared to the AA-/CNTL- subgroup $(\mathrm{Z}=4.31, \mathrm{p}(\operatorname{adj})<.05)$ and the AA-/CNTL+ subgroup $(Z=3.44, p(\operatorname{adj})<.05)$. The AA+/CNTL- subgroup had a significantly higher proportion of individuals who primarily identified as Black/African American compared to the AA-/CNTLsubgroup $(Z=3.30, p(\operatorname{adj})<.05)$. Individuals in the AA+/CNTL+ subgroup were significantly older than those in the AA+/CNTL- subgroup $(\mathrm{p}(\operatorname{adj})=.03)$. Both AA+ subgroups had 
significantly higher BMIs than the AA-/CNTL+ subgroup (Games-Howell p(adj) < .03). Individuals in the AA-/CNTL+ subgroup reported significantly higher income when compared to both CNTL- subgroups (all corrected ps $<.02$ ). No other differences between subgroups were statistically significant after correction for multiple comparisons.

\begin{tabular}{|c|c|c|c|c|c|c|c|}
\hline Measure & Value & $\begin{array}{l}\text { MIDUS-R } \\
\text { Total } \\
N=728\end{array}$ & $\begin{array}{l}\mathrm{AA}+/ \mathrm{CNTL}- \\
\mathrm{n}=62\end{array}$ & $\begin{array}{l}\mathrm{AA}+/ \mathrm{CNTL}+ \\
\mathrm{n}=51\end{array}$ & $\begin{array}{l}\text { AA-/CNTL- } \\
n=183\end{array}$ & $\begin{array}{l}\text { AA-/CNTL+ } \\
n=432\end{array}$ & $\begin{array}{l}\text { Statistic (df) } \\
\text { sig. }\end{array}$ \\
\hline Sex & $\begin{array}{l}\text { \% Female } \\
{[95 \% \text { C] }}\end{array}$ & $\begin{array}{l}49.58 \% \\
{[45.97-53.21]}\end{array}$ & $\begin{array}{l}59.67 \% \\
{[47.25-70.98]}\end{array}$ & $\begin{array}{l}74.51 \% \\
{[61.13-84.45]}\end{array}$ & $\begin{array}{l}40.44 \% \\
{[33.59-47.67]}\end{array}$ & $\begin{array}{l}49.07 \% \\
{[44.38-53.78]}\end{array}$ & $\begin{array}{l}\chi^{2}(3)=18.78 \\
p<.001\end{array}$ \\
\hline $\begin{array}{l}\text { Primary } \\
\text { Race }\end{array}$ & $\begin{array}{l}\% \text { White } \\
{[95 \% \mathrm{Cl})}\end{array}$ & $\begin{array}{l}80.6 \% \\
{[78.02-83.44]}\end{array}$ & $\begin{array}{l}69.4 \% \\
{[59.68-81.31]}\end{array}$ & $\begin{array}{l}68.6 \% \\
{[58.82-82.19]}\end{array}$ & $\begin{array}{l}82.0 \% \\
{[77.04-87.42]}\end{array}$ & $\begin{array}{l}83.1 \% \\
{[78.41-85.12]}\end{array}$ & $\begin{array}{l}\chi^{2}(9)=21.46 \\
p=.011\end{array}$ \\
\hline \multirow[t]{2}{*}{$\begin{array}{l}\text { Age } \\
\text { (Years) }\end{array}$} & $\begin{array}{l}\text { Mean (SD) } \\
{[95 \% \mathrm{Cl}]}\end{array}$ & $\begin{array}{l}53.53(13.68) \\
{[52.54-54.53]}\end{array}$ & $\begin{array}{l}50.44(13.36) \\
{[47.04-53.83]}\end{array}$ & $\begin{array}{l}57.59(13.79) \\
{[49.88-54.01]}\end{array}$ & $\begin{array}{l}51.95(14.16) \\
{[52.90-55.43]}\end{array}$ & $\begin{array}{l}54.17(13.37) \\
{[52.54-54.53]}\end{array}$ & \multirow[t]{2}{*}{$\begin{array}{l}F(3,724)=3.73 \\
p=.011\end{array}$} \\
\hline & Median & 54.00 & 50.50 & 55.00 & 52.00 & 55.00 & \\
\hline \multirow[t]{2}{*}{ BMI } & $\begin{array}{l}\text { Mean (SD) } \\
{[95 \% \mathrm{Cl}]}\end{array}$ & $\begin{array}{l}29.84(7.24) \\
{[29.31-30.36]}\end{array}$ & $\begin{array}{l}32.08(8.16) \\
{[30.01-34.16]}\end{array}$ & $\begin{array}{l}32.36(11.92) \\
{[29.01-35.71]}\end{array}$ & $\begin{array}{l}30.63(6.37) \\
{[29.69-31.57]}\end{array}$ & $\begin{array}{l}28.88(6.49) \\
{[28.27-29.49]}\end{array}$ & \multirow{2}{*}{$\begin{array}{l}\text { Welch } \\
\mathrm{F}(3,135.77)= \\
6.07 \\
\mathrm{p}=.001\end{array}$} \\
\hline & Median & 28.55 & 30.72 & 28.95 & 29.97 & 27.91 & \\
\hline \multirow[t]{2}{*}{$\begin{array}{l}\text { Lag } \\
\text { (Months) }\end{array}$} & $\begin{array}{l}\text { Mean (SD) } \\
{[95 \% \mathrm{Cl}]}\end{array}$ & $\begin{array}{l}22.46(8.92) \\
{[20.53-21.81]}\end{array}$ & $\begin{array}{l}20.55(9.26) \\
{[18.20-22.90]}\end{array}$ & $\begin{array}{l}21.20(8.21) \\
{[18.89-23.51]}\end{array}$ & $\begin{array}{l}20.68(8.41) \\
{[19.45-21.90]}\end{array}$ & $\begin{array}{l}21.46(9.00) \\
{[20.61-22.31]}\end{array}$ & \multirow[t]{2}{*}{$\begin{array}{l}\mathrm{F}(3,724)=.451 \\
\mathrm{p}=.716\end{array}$} \\
\hline & Median & 20.50 & 21.00 & 21.00 & 21.00 & 20.00 & \\
\hline \multirow[t]{2}{*}{$\begin{array}{l}\mathrm{HH} \\
\text { Income } \\
\text { (USD) }\end{array}$} & $\begin{array}{l}\text { Mean } \\
\text { (SD) } \\
{[95 \% \mathrm{Cl}]}\end{array}$ & $\begin{array}{l}90,939.99 \\
(65,662.23) \\
{[86,081.22-} \\
95,798.75]\end{array}$ & $\begin{array}{l}67,967.21 \\
(48,671.68) \\
{[55,501.82-} \\
80,432.61]\end{array}$ & $\begin{array}{l}79,864.58 \\
(59,591.52) \\
{[62,561.01-} \\
97,168.16]\end{array}$ & $\begin{array}{l}81,686.44 \\
(66,075.14) \\
{[71,884.86-} \\
91,488.02]\end{array}$ & $\begin{array}{l}99,482.67 \\
(66,962.54) \\
{[93,044.61-} \\
105,920.70]\end{array}$ & \multirow[t]{2}{*}{$\begin{array}{l}\mathrm{F}(3,700)=6.63 \\
\mathrm{p}<.001\end{array}$} \\
\hline & Median & $89,500.00$ & $71,500.00$ & $73,000.00$ & $63,250.00$ & $89,500.00$ & \\
\hline
\end{tabular}

\subsubsection{Summary of Clustering Effects}

Results indicated that in both MIDUS-2 and MIDUS-R samples, subgroups differed on sex, age, BMI, and income, while differences in race were only observed in the MIDUS-R sample. This sample included a larger percentage of participants oversampled from urban populations, which is reflected in the differences between samples on race. Due to the observed differences between subgroups in each sample (i.e. collinearity of planned covariates with our subgroups), age, sex, and BMI (in both samples) cannot be reliably included in our primary GLM. Evidence 
shows that doing so can substantially reduce power, bias estimates (e.g. exaggerating the effect of sex for one subgroup with higher female to male ratio, while minimizing it in others), and introduce spurious effects (Schneider, Avivi-Reich, \& Mozuraitis, 2015; see also FDA adopted ICH E9 Statistical Procedures for Clinical Trials). Instead we include covariates and relevant subgroup * covariate interactions in a second analysis to test the sensitivity of any findings and include these results in the supplemental materials.

\subsection{Individual Differences in Inflammation by Subgroup}

All inflammatory markers were weakly to moderately correlated within the MIDUS-2 sample (Pearson $r$ Range $=.069$ to $.509, \mathrm{p}<.05)$. These significant correlations were largely replicated in the MIDUS-R sample (Pearson $r$ Range $=.089$ to $.579, \mathrm{p}<.05$ ). However, correlations between LogIL-6 (Z) and LogICAM-1 (Z) (Pearson $r=.053, \mathrm{p}=.155)$ and between $\operatorname{LogCRP}(\mathrm{Z})$ and SIL6-R $(\mathrm{Z})($ Pearson $r=.057, \mathrm{p}=.126)$ were not significant in the MIDUS-R sample. Given that none of these relationships were particularly strong, we elected to run separate univariate GLMs to test the overall main effect and interaction of AA and CNTL levels on each inflammatory marker, covarying for Lag $(Z)$ between sessions. To reduce Type 1 error, we took a conservative approach and used a Bonferroni corrected threshold of alpha $=.008$.

Lag $(Z)$ accounted for a unique portion of the variance across several markers (see Table 4 $\& 5$ ). Above and beyond effects associated with all other predictors and lag, there was a small but significant main effect of AA level on Log IL-6 (Z) and Log CRP (Z) in the MIDUS-2 sample (Figure 3., Table 4). These results were replicated in the MIDUS-R sample (Figure 3, Table 5). There was an additional significant main effect of AA subgroups on FIB (Z). There was no significant main effect of CNTL or AA*CNTL interaction on any of the markers. For all significant effects, individuals in the AA+ subgroup had significantly higher inflammatory marker levels than those in the AA- subgroup (Figure 3). Findings suggest a consistent (between samples) unique effect of subjective arousal on inflammatory markers IL-6 and CRP. 


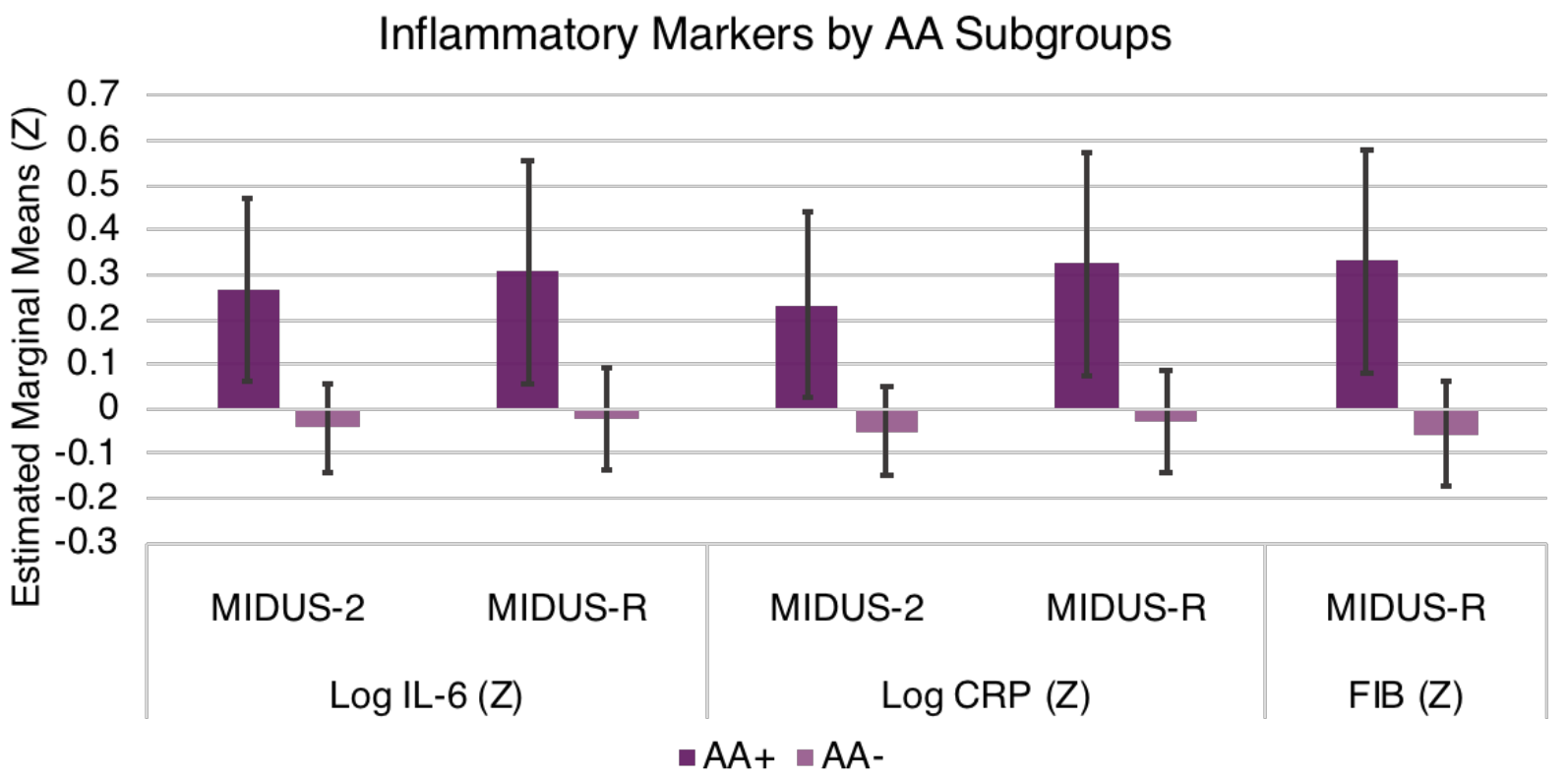

Figure 3. Error bars denote $99.2 \%$ CI. Estimated marginal means for the high arousal group were significantly greater than the grand mean.

\begin{tabular}{|c|c|c|c|c|}
\hline Sample & $\begin{array}{l}\text { Dependent } \\
\text { Variable }\end{array}$ & Predictor & Statistics & $\begin{array}{l}\text { Effect Size } \\
\left(\eta_{p}{ }^{2}\right)\end{array}$ \\
\hline \multirow[t]{21}{*}{ MIDUS-2 } & LogIL6 (Z) & AA Subgroups & $F(1,1025)=13.070, p<0.001$ & 0.013 \\
\hline & & CNTL Subgroups & $F(1,1025)=0.166, p=0.684$ & 0.000 \\
\hline & & $A A * C N T L \operatorname{lntx}$ & $F(1,1025)=0.050, p=0.824$ & 0.000 \\
\hline & & $\operatorname{Lag}(Z)$ & $F(1,1025)=10.008, p=0.002$ & 0.010 \\
\hline & $\operatorname{LogCRP}(Z)$ & AA Subgroups & $F(1,1025)=10.973, p=0.001$ & 0.011 \\
\hline & & CNTL Subgroups & $F(1,1025)=0.033, p=0.856$ & 0.000 \\
\hline & & $A A *$ CNTL Intx & $F(1,1025)=0.011, p=0.917$ & 0.000 \\
\hline & & $\operatorname{Lag}(Z)$ & $F(1,1025)=1.897, p=0.169$ & 0.002 \\
\hline & LogICAM-1 (Z) & AA Subgroups & $F(1,1025)=5.055, p=0.025$ & 0.005 \\
\hline & & CNTL Subgroups & $F(1,1025)=0.151, p=0.698$ & 0.000 \\
\hline & & $A A *$ CNTL Intx & $F(1,1025)=0.297, p=0.586$ & 0.000 \\
\hline & & $\operatorname{Lag}(\mathrm{Z})$ & $F(1,1025)=43.828, p<0.001$ & 0.041 \\
\hline & FIB (Z) & AA Subgroups & $F(1,1025)=0.711, p=0.399$ & 0.001 \\
\hline & & CNTL Subgroups & $F(1,1025)=4.940, p=0.026$ & 0.005 \\
\hline & & $A A * C N T L$ Intx & $F(1,1025)=.390, p=0.532$ & 0.000 \\
\hline & & $\operatorname{Lag}(Z)$ & $F(1,1025)=19.893, p<0.001$ & 0.019 \\
\hline & IL-6SR (Z) & AA Subgroups & $F(1,1025)=.104, p=0.747$ & 0.000 \\
\hline & & CNTL Subgroups & $F(1,1025)=.168, p=0.682$ & 0.000 \\
\hline & & $A A * C N T L \operatorname{lntx}$ & $F(1,1025)=.320, p=0.572$ & 0.000 \\
\hline & & $\operatorname{Lag}(\mathrm{Z})$ & $F(1,1025)=13.103, p<0.001$ & 0.013 \\
\hline & ELAM-1 (Z) & AA Subgroups & $F(1,1025)=0.327, p=0.568$ & 0.000 \\
\hline
\end{tabular}




\begin{tabular}{ccc}
\hline CNTL Subgroups & $F(1,1025)=0.139, p=0.710$ & 0.000 \\
AA* CNTL Intx & $F(1,1025)=0.388, p=0.534$ & 0.000 \\
Lag $(Z)$ & $\mathbf{F ( 1 , 1 0 2 5 )}=\mathbf{2 6 . 3 8 4 , ~} \mathbf{p}<. \mathbf{0 0 1}$ & $\mathbf{0 . 0 2 5}$ \\
\hline All significant (below $\langle=.008)$ linear predictors are noted in bold, those significant below the \\
canonical uncorrected threshold $(\langle=.05)$ are italicized but are not further discussed.
\end{tabular}

\begin{tabular}{|c|c|c|c|c|}
\hline Sample & $\begin{array}{l}\text { Dependent } \\
\text { Variable }\end{array}$ & Predictor & Statistics & $\begin{array}{l}\text { Effect } \\
\text { Size }\left(n_{p}^{2}\right)\end{array}$ \\
\hline \multirow[t]{24}{*}{ MIDUS-R } & LogIL6 (Z) & AA Subgroups & $F(1,723)=10.165, p=0.001$ & 0.014 \\
\hline & & CNTL Subgroups & $F(1,723)=2.501, p=0.114$ & 0.003 \\
\hline & & $A A * C N T L$ Intx & $F(1,723)=0.016, p=0.901$ & 0.000 \\
\hline & & $\operatorname{Lag}(Z)$ & $F(1,723)=4.682, p=0.031$ & 0.006 \\
\hline & $\log C R P(Z)$ & AA Subgroups & $F(1,723)=11.767, p=0.001$ & 0.016 \\
\hline & & CNTL Subgroups & $F(1,723)=0.733, p=0.392$ & 0.001 \\
\hline & & $A A{ }^{*} C N T L \operatorname{lntx}$ & $F(1,723)=0.419, p=0.518$ & 0.001 \\
\hline & & $\operatorname{Lag}(Z)$ & $F(1,723)=0.272, p=0.602$ & 0.000 \\
\hline & LogICAM-1 (Z) & AA Subgroups & $F(1,723)=0.642, p=0.423$ & 0.001 \\
\hline & & CNTL Subgroups & $F(1,723)=2.084, p=0.149$ & 0.003 \\
\hline & & $A A{ }^{*}$ CNTL Intx & $F(1,723)=0.149, p=0.699$ & 0.000 \\
\hline & & $\operatorname{Lag}(Z)$ & $F(1,723)=54.024, p<0.001$ & 0.068 \\
\hline & FIB (Z) & AA Subgroups & $F(1,723)=13.918, p<0.001$ & 0.019 \\
\hline & & CNTL Subgroups & $F(1,723)=0.041, p=0.839$ & 0.000 \\
\hline & & $A A * C N T L \operatorname{lntx}$ & $F(1,723)=0.001, p=0.981$ & 0.000 \\
\hline & & $\operatorname{Lag}(Z)$ & $F(1,723)=2.156, p=0.142$ & 0.003 \\
\hline & IL-6SR (Z) & AA Subgroups & $F(1,723)=0.068, p=0.795$ & 0.000 \\
\hline & & CNTL Subgroups & $F(1,723)=0.995, p=0.319$ & 0.001 \\
\hline & & $A A * C N T L$ Intx & $F(1,723)=0.002, p=0.968$ & 0.000 \\
\hline & & $\operatorname{Lag}(Z)$ & $F(1,723)=0.280, p=0.597$ & 0.000 \\
\hline & ELAM-1 (Z) & AA Subgroups & $F(1,723)=2.279, p=0.132$ & 0.003 \\
\hline & & CNTL Subgroups & $F(1,723)=4.232, p=0.040$ & 0.006 \\
\hline & & $A A * C N T L$ Intx & $F(1,723)=0.719, p=0.397$ & 0.001 \\
\hline & & $\operatorname{Lag}(Z)$ & $F(1,723)=4.333, p=0.038$ & 0.006 \\
\hline
\end{tabular}

All significant (below $\langle=.008$ ) linear predictors are noted in bold, those significant below the canonical uncorrected threshold $(\langle=.05)$ are italicized.

\subsection{Differences among Subgroups in Affective Domains}

\subsubsection{Subgroup Differences in Negative Affective Domains}

MASQ Depressive distress and MASQ anxious distress scores were moderately and significantly correlated in each sample (MIDUS-2 Spearman's rho $=.619, \mathrm{p}<.001$; MIDUS-R 
Spearman's rho $=.630, \mathrm{p}<.001)$. Assumptions of equality of variance (Levene's test) and covariance (Box's Test and visual inspection of variance spread plots) were not met (all ps $<.001$ ). Given that these tests are highly sensitive to unequal sample sizes between factor levels, we ran both parametric (separate univariate GLMs) and non-parametric (Kruskal-Wallis) tests. There were no qualitative differences in the tested effects and as such we report the results of the parametric tests to simplify interpretation of the findings. To minimize Type 1 error, given that both depressive distress and anxious distress are within the negative affect domain, we used a Bonferroni corrected alpha threshold of .025 .

Table 6. Parameter Estimates for Negative Affect Symptom Domains

\begin{tabular}{|c|c|c|c|c|c|c|c|c|c|}
\hline \multirow[t]{2}{*}{$\begin{array}{l}\text { Dependent } \\
\text { Variable }\end{array}$} & \multirow[t]{2}{*}{ Sample } & \multirow[t]{2}{*}{ Predictor } & \multirow[t]{2}{*}{$\boldsymbol{\beta}$} & \multirow[t]{2}{*}{$\begin{array}{l}\text { Std. } \\
\text { Error }\end{array}$} & \multirow[t]{2}{*}{$\mathbf{t}$} & \multirow[t]{2}{*}{$\mathbf{p}$} & \multicolumn{2}{|c|}{$\begin{array}{l}97.5 \% \\
\text { Confidence } \\
\text { Interval }\end{array}$} & \multirow[t]{2}{*}{$\begin{array}{l}\text { Effect } \\
\text { Size } \\
\left(n_{p}{ }^{2}\right)\end{array}$} \\
\hline & & & & & & & $\begin{array}{l}\text { Lower } \\
\text { Bound }\end{array}$ & $\begin{array}{l}\text { Upper } \\
\text { Bound }\end{array}$ & \\
\hline \multirow{10}{*}{$\begin{array}{l}\text { Depressive } \\
\text { Distress (Z) }\end{array}$} & \multirow[t]{5}{*}{ MIDUS-2 } & Intercept & -0.265 & 0.036 & -7.301 & 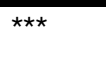 & -0.346 & -0.183 & 0.049 \\
\hline & & $\operatorname{Lag}(Z)$ & $4.224 \times 10^{-5}$ & 0.028 & 0.002 & 0.999 & -0.062 & 0.063 & 0.000 \\
\hline & & $A A+=1$ & 0.551 & 0.111 & 4.976 & $\star \star \star ~$ & 0.302 & 0.799 & 0.024 \\
\hline & & CNTL- = 1 & 0.323 & 0.067 & 4.847 & $* \star \star$ & 0.173 & 0.473 & 0.022 \\
\hline & & $\mathrm{AA}+/ \mathrm{CNTL}-=1$ & 0.691 & 0.154 & 4.490 & $* \star \star$ & 0.346 & 1.037 & 0.019 \\
\hline & \multirow[t]{5}{*}{ MIDUS-R } & Intercept & -0.325 & 0.042 & -7.755 & $\star \star \star$ & -0.419 & -0.231 & 0.077 \\
\hline & & $\operatorname{Lag}(Z)$ & 0.069 & 0.032 & 2.152 & 0.032 & -0.003 & 0.142 & 0.006 \\
\hline & & $A A+=1$ & 0.576 & 0.129 & 4.472 & $* \star \star$ & 0.287 & 0.865 & 0.027 \\
\hline & & CNTL- = 1 & 0.549 & 0.077 & 7.151 & $* \star *$ & 0.377 & 0.721 & 0.066 \\
\hline & & $\mathrm{AA}+/ \mathrm{CNTL}-=1$ & 0.593 & 0.181 & 3.267 & 0.001 & 0.185 & 1.000 & 0.015 \\
\hline \multirow{10}{*}{$\begin{array}{l}\text { Anxious } \\
\text { Distress (Z) }\end{array}$} & \multirow[t]{5}{*}{ MIDUS-2 } & Intercept & -0.304 & 0.036 & -8.541 & $* * *$ & -0.384 & -0.224 & 0.066 \\
\hline & & $\operatorname{Lag}(Z)$ & 0.003 & 0.027 & 0.100 & 0.920 & -0.059 & 0.064 & 0.000 \\
\hline & & $A A+=1$ & 0.912 & 0.109 & 8.400 & $\star \star \star *$ & 0.668 & 1.156 & 0.064 \\
\hline & & CNTL- = 1 & 0.369 & 0.065 & 5.646 & $* * *$ & 0.222 & 0.516 & 0.030 \\
\hline & & $\mathrm{AA}+/ \mathrm{CNTL}-=1$ & 0.306 & 0.151 & 2.027 & 0.043 & -0.033 & 0.645 & 0.004 \\
\hline & \multirow[t]{5}{*}{ MIDUS-R } & Intercept & -0.346 & 0.040 & -8.604 & 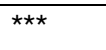 & -0.436 & -0.256 & 0.093 \\
\hline & & $\operatorname{Lag}(Z)$ & 0.032 & 0.031 & 1.034 & 0.302 & -0.038 & 0.102 & 0.001 \\
\hline & & $A A+=1$ & 1.010 & 0.124 & 8.165 & 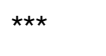 & 0.732 & 1.288 & 0.084 \\
\hline & & CNTL- = 1 & 0.458 & 0.074 & 6.210 & $\star \star \star ~$ & 0.292 & 0.624 & 0.051 \\
\hline & & $\mathrm{AA}+/ \mathrm{CNTL}-=1$ & 0.412 & 0.174 & 2.362 & 0.018 & 0.020 & 0.803 & 0.008 \\
\hline
\end{tabular}

${ }_{\star \star \star} \mathrm{p}<.001$

$1=$ yes

Intercept represents the marginal mean of the AA-/CNTL- (reference) subgroup. 
In the MIDUS-2 sample, there was a significant main effect of AA, CNTL, and AA*CNTL interaction on standardized $(Z)$ depressive distress (Full model: adj. $\mathrm{R}^{2}{ }_{\mathrm{DD}}=.203$ ) and anxious distress $(\mathrm{Z})$ (Full model: adj. $\left.\mathrm{R}^{2} \mathrm{AD}=.232\right)$. This effect was replicated in the MIDUS-R sample (Full Model: MIDUS-R adj. $\mathrm{R}^{2} \mathrm{DD}=.243$; adj. $\mathrm{R}^{2}{ }_{\mathrm{AD}}=.302$ ). See tables 6 and 7 for summary of statistical tests and parameter estimates. Each reported effect is unique above and beyond the variance accounted for by other variables in the model.

\begin{tabular}{|c|c|c|c|c|}
\hline Sample & DV & Predictors & Statistics & $\begin{array}{l}\text { Effect } \\
\text { Size } \\
\left(n_{p}{ }^{2}\right)\end{array}$ \\
\hline \multirow{8}{*}{ MIDUS-2 } & & $\operatorname{Lag}(\mathrm{Z})$ & $F(1,1025)=0.000, p=0.999$ & 0.000 \\
\hline & Depressive & AA Subgroups & $F(1,1025)=135.668, p<.001$ & 0.117 \\
\hline & Distress (Z) & CNTL Subgroups & $F(1,1025)=75.469, p<.001$ & 0.069 \\
\hline & & $\mathrm{AA}^{*} \mathrm{CNTL} \ln \mathrm{x}$ & $F(1,1025)=20.163, p<.001$ & .019 \\
\hline & & $\operatorname{Lag}(\mathrm{Z})$ & $F(1,1025)=0.010, p=0.920$ & 0.000 \\
\hline & Anxious & AA Subgroups & $F(1,1025)=199.047, p<.001$ & 0.163 \\
\hline & Distress $(Z)$ & CNTL Subgroups & $F(1,1025)=47.837, p<.001$ & 0.045 \\
\hline & & $\mathrm{AA}^{*} \mathrm{CNTL} \operatorname{lntx}$ & $F(1,1025)=4.110, p<.043$ & 0.004 \\
\hline \multirow{8}{*}{ MIDUS-R } & & $\operatorname{Lag}(\mathrm{Z})$ & $F(1,723)=4.632, p=0.032$ & 0.006 \\
\hline & Depressive & AA Subgroups & $F(1,723)=92.469, p<.001$ & 0.113 \\
\hline & Distress $(Z)$ & CNTL Subgroups & $F(1,723)=86.765, p<.001$ & 0.107 \\
\hline & & $\mathrm{AA}^{*} \mathrm{CNTL} \ln \mathrm{x}$ & $F(1,723)=10.675, p=.001$ & 0.015 \\
\hline & & $\operatorname{Lag}(\mathrm{Z})$ & $F(1,723)=1.069, p=0.302$ & 0.001 \\
\hline & Anxious & AA Subgroups & $F(1,723)=194.676, p<.001$ & 0.212 \\
\hline & Distress (Z) & CNTL Subgroups & $F(1,723)=57.965, p<.001$ & 0.074 \\
\hline & & $\mathrm{AA}^{*} \mathrm{CNTL} \ln \mathrm{x}$ & $F(1,723)=5.577, p=.018$ & 0.008 \\
\hline
\end{tabular}

All effects below alpha threshold $=.025$ are noted in bold; effects that are below canonical alpha $<.05$ are italicized.

Further evaluating the interaction (Figure 4), the results showed that high AA is predictive of higher depressive distress $(Z)$ relative to the grand mean and relative to both low AA subgroups only when CNTL is also low. Mean depressive distress scores (Z) from the AA+/CNTL+ and AA/CNTL- subgroups were at or below the grand mean, not statistically different from each other, significantly higher than the AA-/CNTL+ subgroup, and significantly lower than the AA+/CNTL- 
subgroup. These results were consistent across both MIDUS-2 and MIDUS-R samples and suggest that while low arousal and high control each independently contribute to higher symptoms of depressive distress, their combined multiplicative effect is predictive even greater severity. The effect of high arousal is substantially reduced or moderated (Baron and Kenny, 1989), when CNTL is high making it comparable to symptoms reported by the low AA, low CNTL subgroup and to the overall sample mean.

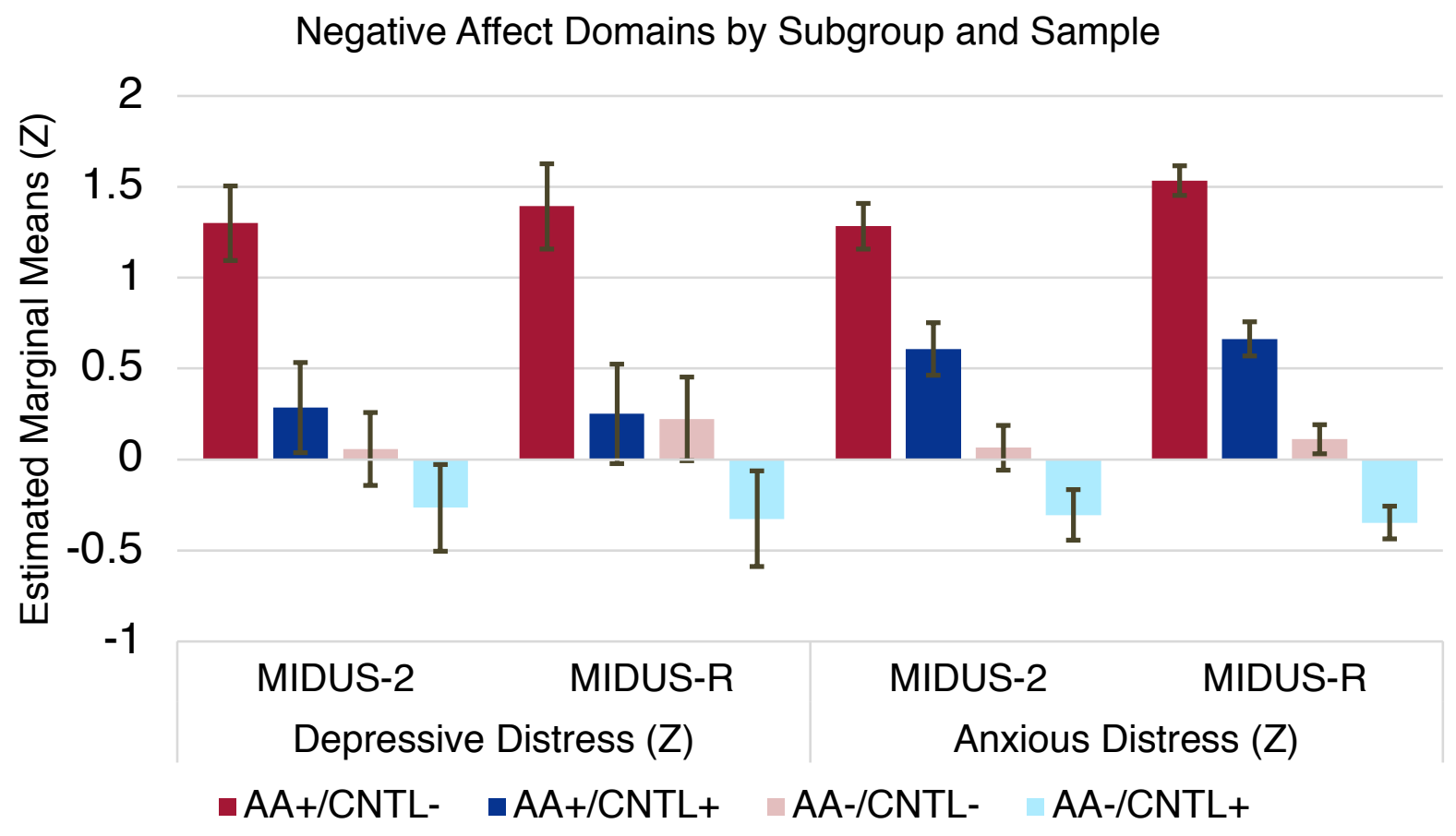

Figure 4 The figure above shows model-based marginal means for each subgroup and in each sample after holding Lag (Z) constant. Confidence intervals are shown at $97.5 \%$. Non-overlapping error bars suggest differences at alpha $<.025$.

A similar subgroup pattern was observed for anxious distress scores (Z), with the exception that all subgroups were significantly different from another. The AA+/CNTL- subgroup had the highest estimated means for anxious distress, followed by the AA+/CNTL+, AA-/CNTL-, and AA-/CNTL+ subgroups (Figure 4; Tables 6 \& 7). Both AA+ subgroups had anxious distress scores (Z) that were significantly greater than the grand mean, and only the AA-/CNTL+ subgroup had estimated scores significantly below the grand mean. Violin plots summarizing the distribution 
(optimally smoothed rotated kernal density plots) of scores in each subgroup are depicted in Figure 5 for both samples.
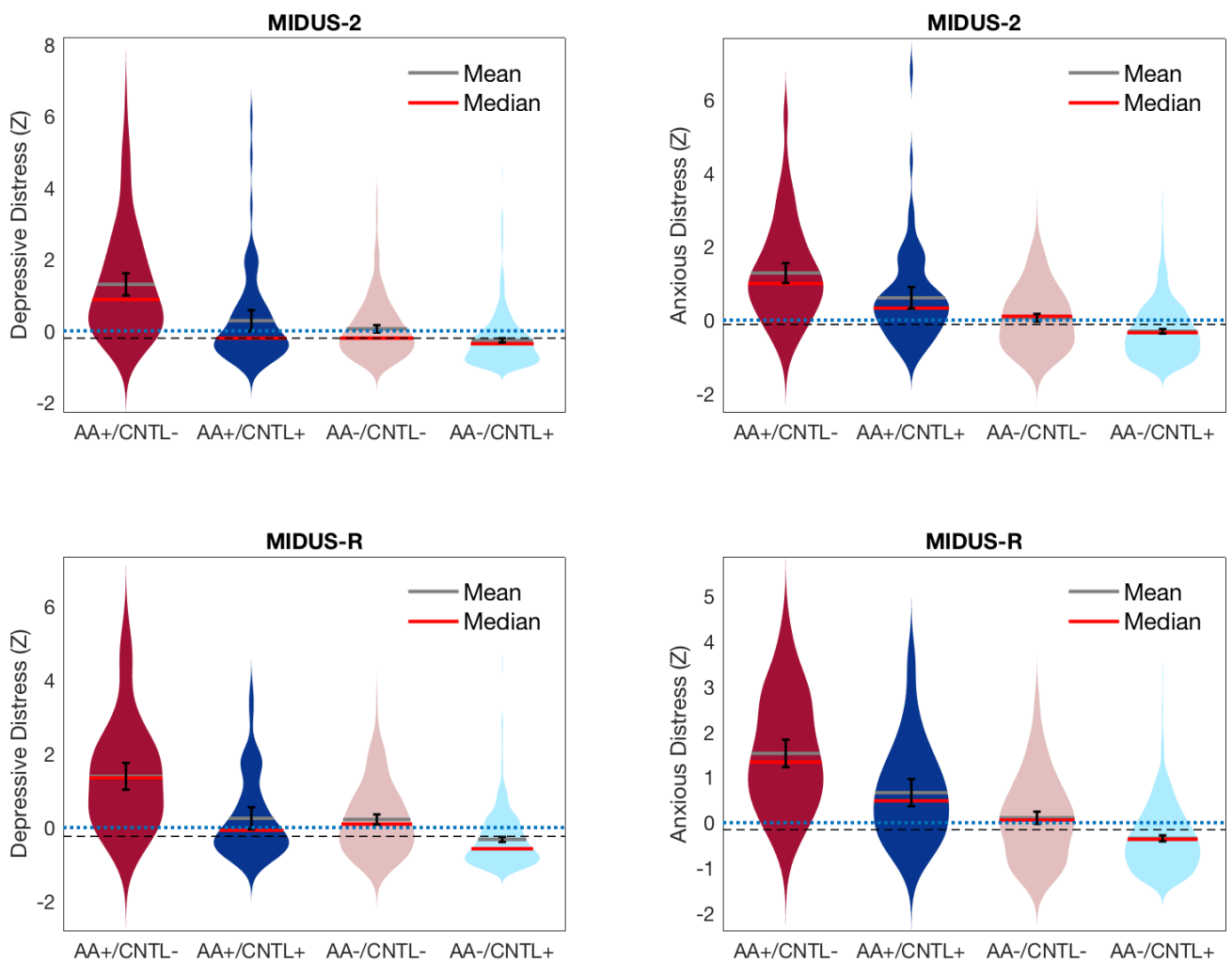

Figure 5. Violin plots above show rotated kernal density plots (smoothing kernal optimized for each subgroup). These plots show the distribution of standardized raw depressive distress and anxious distress scores for each subgroup, the mean of each subgroup in red, the median of each subgroup in gray, the $95 \% \mathrm{CI}$ of the mean (error bars), and a blue dotted line depicting the total sample mean, and a black dashed line representing the median of the sample. Top Left: MIDUS-2 subgroup distributions for depressive distress scores (Z). Top Right: MIDUS-2 subgroup distributions for anxious distress scores (Z). Bottom Left: MIDUS-R subgroup distributions for depressive distress scores (Z). Bottom Right: MIDUS-R subgroup distributions for anxious distress scores (Z). In both samples, a larger proportion of the distribution for the AA+/CNTL- subgroup falls above the mean and median compared to all other subgroups for depressive distress and anxious distress. Nonoverlapping error bars depict significant differences in means $(\mathrm{p}<.05)$. 


\subsubsection{Subgroup Differences in Domains of Anhedonia}

Standardized MASQ Loss of Interest and MASQ Positive Affect scores were moderately and significantly correlated in each sample (MIDUS-2 Spearman's rho $=-.479, \mathrm{p}<.001$; MIDUSR Spearman's rho $=-.440, \mathrm{p}<.001)$. We ran separate GLM models to test the main effect and interaction of AA and CNTL, covarying for Lag (Z), on each of the dependent variables. Procedures for the primary model were identical to that used in for variables in the negative affect domain.

In the MIDUS-2 sample there was a significant main effect of AA subgroups, CNTL subgroups, and AA*CNTL interaction on standardized (Z) Loss of Interest scores (Full model: MIDUS-2 adj. $\mathrm{R}^{2}=.261$ ). These results were replicated in the MIDUS-R sample (Full model: MIDSU-R adj. $\mathrm{R}^{2}=.265$ ) (See table $8 \& 9$ ). Pairwise t-tests indicate that individuals in the $\mathrm{AA}+/ \mathrm{CNTL}-$ subgroup reported significantly higher Loss of Interest $(\mathrm{Z})$ relative to all other subgroups (Figure 6). There were no significant differences in marginal means for Loss of Interest (Z) between AA+/CNT+ and AA-/CNTL- subgroups, but both showed significantly higher scores when compared to the AA-/CNTL+ subgroup. These results were replicated in the MIDUS-R sample (Figures 6). Violin plots summarizing the distribution (optimally smoothed rotated kernel density plots) with measures of central tendency for raw standardized scores in each subgroup are depicted in Figure 7 for both samples.

Table 8. Between-Subject Effects for Symptoms of Anhedonia

\begin{tabular}{|c|c|c|c|c|}
\hline Sample & DV & Predictors & Statistics & $\begin{array}{l}\text { Effect Size } \\
\left(n_{p}^{2}\right)\end{array}$ \\
\hline & & $\operatorname{Lag}(Z)$ & $F(1,1025)=0.075, p=0.784$ & 0.000 \\
\hline & & AA Subgroups & $F(1,1025)=186.335, p<.001$ & 0.154 \\
\hline & Loss of Interest & CNTL Subgroups & $F(1,1025)=105.180, p<.001$ & 0.093 \\
\hline & $(Z)$ & $\mathrm{AA}^{*} \mathrm{CNTL} \ln \mathrm{tx}$ & $F(1,1025)=26.700, p<.001$ & 0.025 \\
\hline \multirow[t]{2}{*}{ MIDUS-2 } & Positive Affect & $\operatorname{Lag}(\mathrm{Z})$ & $F(1,1025)=0.001, p=0.979$ & 0.000 \\
\hline & $(\mathrm{Z})$ & AA Subgroups & $F(1,1025)=23.237, p<.001$ & 0.022 \\
\hline
\end{tabular}




\begin{tabular}{|c|c|c|c|c|}
\hline & & \multirow{2}{*}{$\begin{array}{l}\text { CNTL Subgroups } \\
A^{\star} \text { CNTL Intx }\end{array}$} & \multirow{2}{*}{$\begin{array}{l}F(1,1025)=46.074, p<.001 \\
F(1,1025)=.590, p=.443\end{array}$} & \multirow{2}{*}{$\begin{array}{l}0.043 \\
0.001\end{array}$} \\
\hline & & & & \\
\hline & & $\operatorname{Lag}(Z)$ & $F(1,723)=.037, p=0.848$ & 0.000 \\
\hline & & AA Subgroups & $F(1,723)=128.753, p<.001$ & 0.151 \\
\hline & Loss of Interest & ${ }_{t}$ CNTL Subgroups & $F(1,723)=71.582, p<.001$ & 0.090 \\
\hline & $\underline{(Z)}$ & $A A^{\star} C N T L \operatorname{lnt} x$ & $F(1,723)=5.640, p=.018$ & 0.008 \\
\hline & & $\operatorname{Lag}(Z)$ & $F(1,723)=0.033, p=0.855$ & 0.000 \\
\hline & & AA Subgroups & $F(1,723)=7.664, p=.006$ & 0.010 \\
\hline & Positive Affect & CNTL Subgroups & $F(1,723)=60.975, p<.001$ & 0.078 \\
\hline MIDUS-R & $(Z)$ & $A A^{*} C N T L \operatorname{lnt} x$ & $F(1,723)=1.533, p=.216$ & 0.002 \\
\hline
\end{tabular}

\section{Table 9. Parameter Estimates for Anhedonia Symptom Domains}

\begin{tabular}{|c|c|c|c|c|c|c|c|c|c|}
\hline \multirow[t]{2}{*}{$\begin{array}{l}\text { Dependent } \\
\text { Variable }\end{array}$} & \multirow[t]{2}{*}{ Sample } & \multirow[t]{2}{*}{ Predictor } & \multirow[t]{2}{*}{$\boldsymbol{\beta}$} & \multirow[t]{2}{*}{$\begin{array}{l}\text { Std. } \\
\text { Error }\end{array}$} & \multirow[t]{2}{*}{$\mathbf{t}$} & \multirow[t]{2}{*}{$\mathbf{p}$} & \multicolumn{2}{|c|}{$\begin{array}{c}97.5 \% \text { Confidenc } \\
\text { Interval }\end{array}$} & \multirow[t]{2}{*}{$\begin{array}{l}\text { Effect } \\
\text { Size } \\
\left(\eta_{p}{ }^{2}\right) \\
\end{array}$} \\
\hline & & & & & & & $\begin{array}{l}\text { Lower } \\
\text { Bound }\end{array}$ & $\begin{array}{l}\text { Upper } \\
\text { Bound }\end{array}$ & \\
\hline \multirow{10}{*}{$\begin{array}{l}\text { Loss of } \\
\text { Interest (Z) }\end{array}$} & \multirow[t]{5}{*}{ MIDUS-2 } & Intercept & -0.303 & 0.035 & -8.675 & 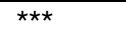 & -0.381 & -0.225 & 0.068 \\
\hline & & $\operatorname{Lag}(Z)$ & -0.007 & 0.027 & -0.274 & 0.784 & -0.068 & 0.053 & 0.000 \\
\hline & & $\mathrm{AA}+=1$ & 0.628 & 0.106 & 5.898 & $* \star *$ & 0.389 & 0.867 & 0.033 \\
\hline & & CNTL- $=1$ & 0.377 & 0.064 & 5.877 & 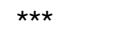 & 0.233 & 0.521 & 0.033 \\
\hline & & $\mathrm{AA}+/ \mathrm{CNTL}-=1$ & 0.765 & 0.148 & 5.167 & $\star \star \star \star$ & 0.433 & 1.098 & 0.025 \\
\hline & \multirow[t]{5}{*}{ MIDUS-R } & Intercept & -0.344 & 0.041 & -8.336 & $* \star \star$ & -0.437 & -0.251 & 0.088 \\
\hline & & $\operatorname{Lag}(Z)$ & 0.006 & 0.032 & 0.191 & 0.848 & -0.065 & 0.078 & 0.000 \\
\hline & & $\mathrm{AA}+=1$ & 0.802 & 0.127 & 6.320 & 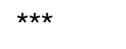 & 0.517 & 1.088 & 0.052 \\
\hline & & CNTL- $=1$ & 0.545 & 0.076 & 7.196 & $* \star *$ & 0.375 & 0.715 & 0.067 \\
\hline & & $\mathrm{AA}+/ \mathrm{CNTL}-=1$ & 0.425 & 0.179 & 2.375 & 0.018 & 0.023 & 0.827 & 0.008 \\
\hline \multirow{10}{*}{$\begin{array}{l}\text { Positive } \\
\text { Affect (Z) }\end{array}$} & \multirow[t]{5}{*}{ MIDUS-2 } & Intercept & 0.235 & 0.039 & 6.066 & $* \star \star *$ & 0.148 & 0.321 & 0.035 \\
\hline & & $\operatorname{Lag}(Z)$ & 0.001 & 0.030 & 0.027 & 0.979 & -0.066 & 0.067 & 0.000 \\
\hline & & $\mathrm{AA}+=1$ & -0.332 & 0.118 & -2.818 & 0.005 & -0.597 & -0.068 & 0.008 \\
\hline & & CNTL- $=1$ & -0.494 & 0.071 & -6.951 & 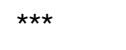 & -0.653 & -0.334 & 0.045 \\
\hline & & $\mathrm{AA}+/ \mathrm{CNTL}-=1$ & -0.126 & 0.164 & -0.768 & 0.443 & -0.494 & 0.242 & 0.001 \\
\hline & \multirow[t]{5}{*}{$\overline{M I D U S-R}$} & Intercept & 0.260 & 0.045 & 5.766 & *** & 0.159 & 0.361 & 0.044 \\
\hline & & $\operatorname{Lag}(Z)$ & 0.006 & 0.035 & 0.182 & 0.855 & -0.072 & 0.084 & 0.000 \\
\hline & & $\mathrm{AA}+=1$ & -0.149 & 0.139 & -1.078 & 0.281 & -0.461 & 0.162 & 0.002 \\
\hline & & CNTL- $=1$ & -0.642 & 0.083 & -7.768 & $\star \star \star *$ & -0.827 & -0.456 & 0.077 \\
\hline & & $\mathrm{AA}+/ \mathrm{CNTL}-=1$ & -0.242 & 0.195 & -1.238 & 0.216 & -0.680 & 0.197 & 0.002 \\
\hline \multicolumn{10}{|l|}{$\overline{\star \star \star} p<.001$} \\
\hline 1 = yes & & & & & & & & & \\
\hline
\end{tabular}




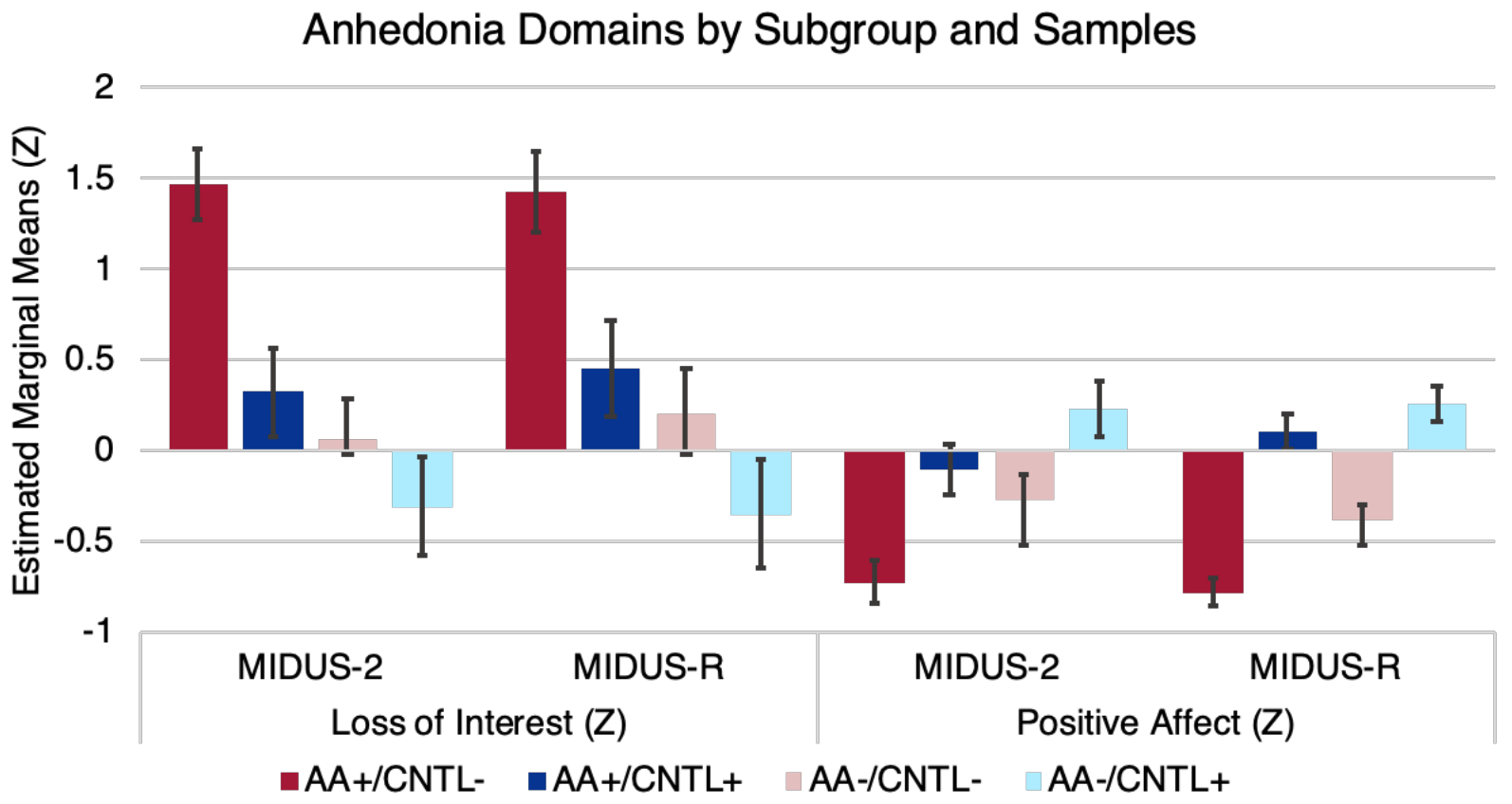

Figure 6 The figure above shows model estimated marginal means for each subgroup and in each sample after holding Lag (Z) constant. Confidence intervals are shown at 97.5\%. Non-overlapping error bars suggest differences at alpha $<.025$.
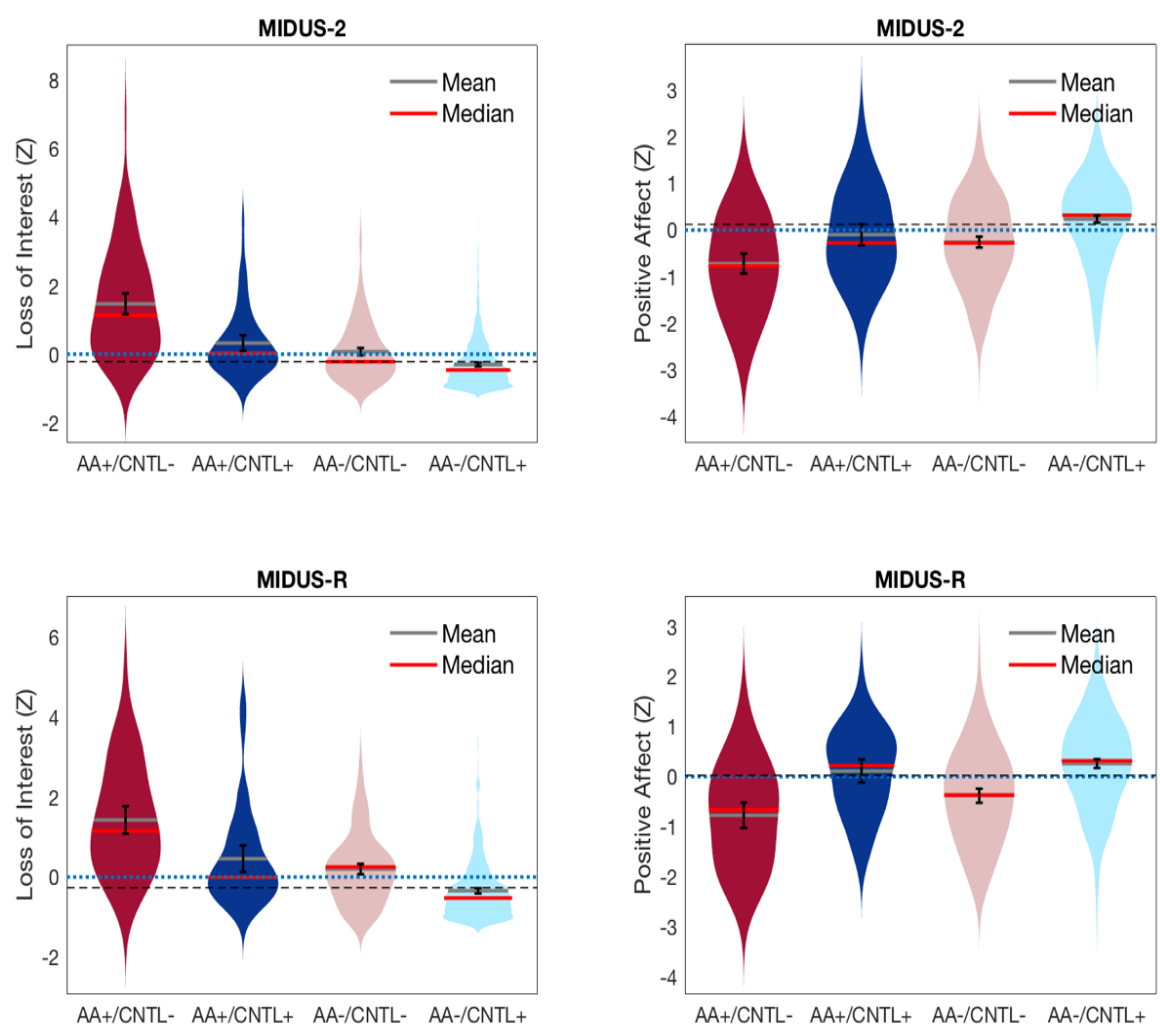
Figure 7. Violin plots depicted above show rotated kernal density plots (smoothing kernal optimized for each subgroup). These plots show the distribution of standardized raw scores for each subgroup, the mean of each subgroup in red, the median of each subgroup in gray, the $95 \%$ CI of the mean (error bars), a blue dotted line depicting the total sample mean, and a black dashed line representing the median of the sample. Top Left: MIDUS-2 subgroup distributions for loss of interest (Z). Top Right: MIDUS-2 subgroup distributions for positive affect (Z). Bottom Left: MIDUS-R subgroup distributions for loss of interest (Z). Bottom Right: MIDUS-R subgroup distributions for positive affect (Z). In both samples, a larger proportion of the distribution for the AA+/CNTL- subgroup falls above the mean and median compared to all other subgroups for loss of interest. In positive affect, a larger proportion of the AA+/CNTL- and AA-/CNTLsubgroups (respectively), fall below the sample mean. Non-overlapping error bars depict significant differences in means $(\mathrm{p}<.05)$.

For Positive Affect (Z), there were significant unique main effects of AA and CNTL in the MIDUS-2 sample and no significant interaction (Full model: MIDUS-2 adj. $\mathrm{R}^{2}=.094$ ). These results were replicated in the MIDUS-R sample (Full model: MIDUS-R adj. $\mathrm{R}^{2}=.124$ ). Figure 5 shows that individuals in the AA+/CNTL- subgroup had significantly lower estimated PA scores (Z) compared to all other subgroups. There was no significant difference in mean PA scores (Z) between $\mathrm{AA}+/ \mathrm{CNTL}+$ and AA-/CNTL- subgroups. Estimated mean PA (Z) values were only below the sample mean for the two CNTL- subgroups (Figure 6 and 7). These effects were largely replicated in the MIDUS-R sample. However, in this sample, the difference between AA+/CNTL+ and AA-/CNTL- subgroups was also significant (Figure 6). Both CNTL- subgroups had significantly lower PA scores $(Z)$ when independently compared to either CNTL+ subgroup. There were no significant differences between CNTL+ subgroups, and both had estimated PA $(Z)$ scores that were above the total sample mean. Consistent with the MIDUS-2 sample, means for both CNTL- subgroups were significantly below the sample mean.

\subsection{Exploratory Analyses: Prevalence of Chronic Pathology}

We conducted exploratory chi-squared tests to determine whether the elevations in symptoms reported above translated into subgroup differences in prevalence for diagnosable psychopathology. The 12-month prevalence of anhedonia, anxiety disorder, panic attack, and 
depressed affect refers to whether participants met DSM-IV clinical criteria for symptoms in that domain at any point during the past year based on questions asked by researchers in the study. The other two variables refer to self-reported diagnoses of depression/anxiety/emotional disorder during the past 12 months, and self-reported diagnoses of depression ever (lifetime). There was a significant effect of subgroup for all variables tested in both MIDUS-2 and MIDUS-R samples (Table 10).

\begin{tabular}{l|lll} 
Psychopathological Domain & \multicolumn{1}{l}{ Sample } & $\chi^{2}$ & Sig. $(\mathrm{p})$ \\
\hline Anhedonia (12 Months) & MIDUS-2 & 22.51 & $\mathrm{p}<.001$ \\
& MIDUS-R & 10.07 & $\mathrm{p}=.018$ \\
Anxiety Disorder (12 Months) & MIDUS-2 & 34.99 & $\mathrm{p}<.001$ \\
& MIDUS-R & 32.56 & $\mathrm{p}<.001$ \\
Panic Attack (12 Months) & MIDUS-2 & 34.43 & $\mathrm{p}<.001$ \\
& MIDUS-R & 36.51 & $\mathrm{p}<.001$ \\
Depressed Affect (12 Months) & MIDUS-2 & 99.80 & $\mathrm{p}<.001$ \\
& MIDUS-R & 36.26 & $\mathrm{p}<.001$ \\
Anxiety/Depression/Emotional & MIDUS-2 & 73.62 & $\mathrm{p}<.001$ \\
Disorder (12 Months) & & & \\
& MIDUS-R & 72.07 & $\mathrm{p}<.001$ \\
Depression Ever (Lifetime) & MIDUS-2 & 49.07 & $\mathrm{p}<.001$ \\
& MIDUS-R & 69.71 & $\mathrm{p}<.001$
\end{tabular}

We calculated prevalence ratios for all subgroups against the total sample prevalence and found that in all cases, individuals in the AA+/CNTL- subgroup showed the highest overall prevalence ratios. We depict these prevalence ratios for each sample in Figure 8 and have included them further separated by sex in the supplementary materials (Supplementary Figures $2 \& 3$ ). 


\section{Prevalence Ratios for Psychopathology by Subgroup}

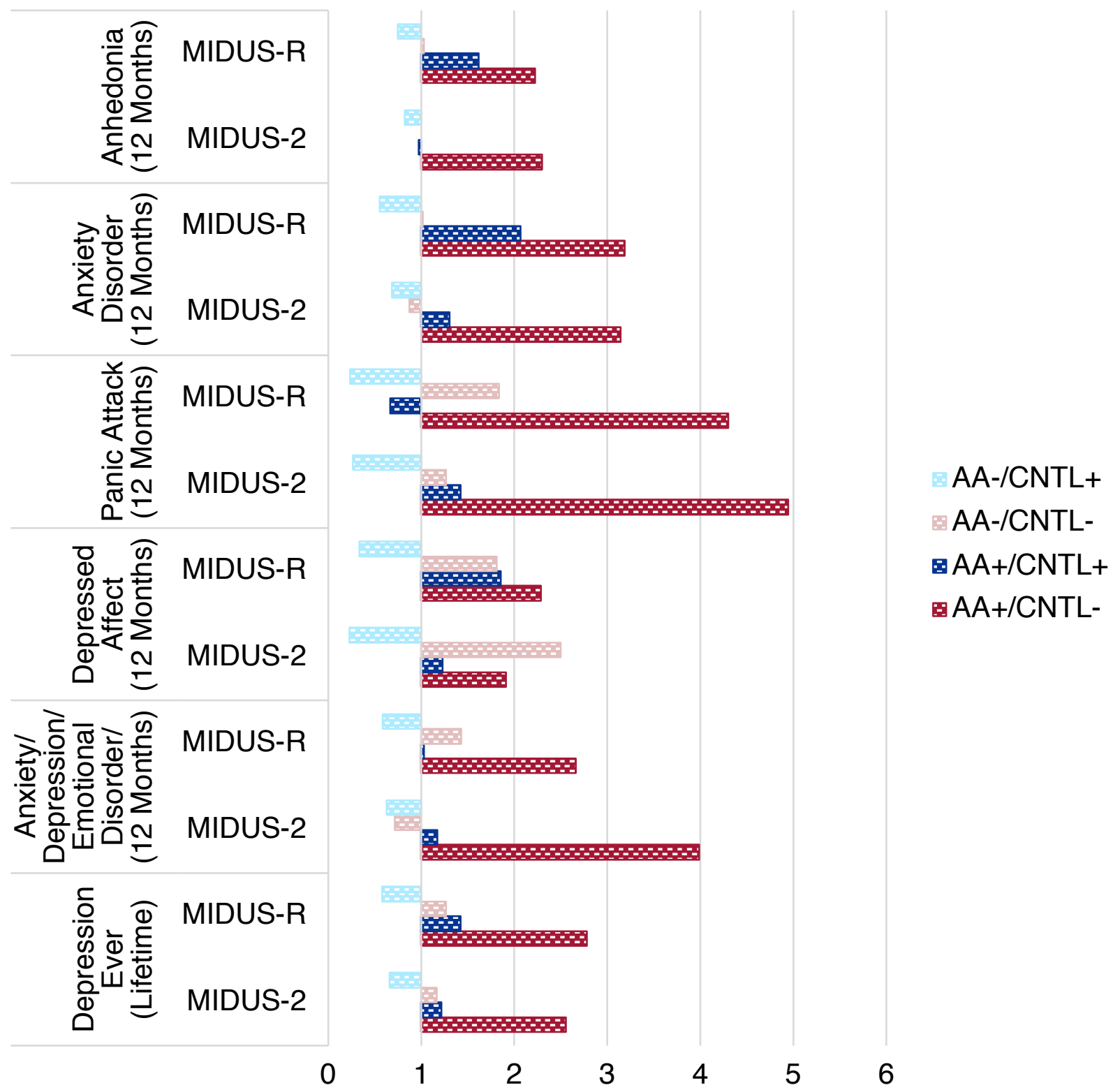

Figure 8. In both samples, individuals in the AA+/CNTL- subgroup consistently had the highest prevalence ratios. The prevalence of psychopathology in this subsample ranged between 2.2-4.9 in the MIDUS-2 and 1.9-4.3 in the MIDUS-R samples. Prevalence ratios for the AA+/CNTL+ subgroup ranged between .96-1.85 in the MIDUS-2 and 67-2.07 in the MIDUS-R sample. For the AA-/CNT- subgroup, prevalence ratios ranged between .71-2.5 in the MIDUS-2 and 1.01-1.83 in the MIDUS-R samples. The AA-/CNTL+ subgroup had prevalence ratios that were all below the sample mean. 


\section{Discussion}

The principal aim of this study was to test the unique and combined contributions of subjective arousal and perceived control on inflammatory and affective outcomes in a large sample of adults from the general population. Our subgrouping method allowed us to study these effects systematically by creating pairs of subgroups that were homogeneous in one dimension (e.g. subjective arousal) and different in the other (e.g. perceived control; and vice versa). The subgroupings created in the MIDUS-2 sample replicated in the separate and more demographically diverse sample from the MIDUS-R, suggesting subgroupings based on high and low levels of subjective arousal and perceived control represent patterns found in the general population of U.S. adults. Further, the current findings show dissociable effects of subjective arousal and perceived control on inflammatory and affective outcomes, and that individual differences in these two domains may help us better understand domain specific heterogeneity in terms of risk and resilience. Across both samples and in line with hypotheses, we found evidence that high subjective arousal predicted increased proinflammatory marker levels relative to low subjective arousal and relative to grand means. We tested whether perceived control had a unique additive or multiplicative effect on pro-inflammatory marker levels and found that it did not. However, consistent with evidence from rodent models of pathological stress (Koolhaas et al., 2011), the subgroup expressing high arousal paired with low perceived control showed much greater severity in symptoms of mood and anxiety compared to every other subgroup and the sample means. We also found that individuals in either of the low control subgroups showed attenuated positive affect with respect to the overall sample mean (while the high control subgroups did not), suggesting a 
unique effect of perceived control on reduced hedonic capacity (Bogdan, Pringle, Goetz \& Pizzagalli, 2012; MacAulay, McGovern \& Cohen, 2014). We demonstrated replicable evidence that individual differences in both subjective arousal and perceived control, revealed distinct patterns of clinically relevant heterogeneity that co-occurred with high and low inflammation. This heterogeneity would have otherwise been masked had either dimension been looked at independently.

Effect of Subjective Arousal on IL-6, CRP, and FIB

In both samples, we found that high arousal, relative to low, predicted higher levels of IL6 and CRP. These effects largely remained, even after accounting for additional unique variance attributed to age, lag, and sex (and their subgroup interactions) (See Supplementary Results). Of note, we found an arousal by sex interaction on CRP levels in the MIDUS-2 sample. At low arousal, females showed higher levels of CRP compared to males and no change from low to high arousal while males showed a significant arousal-related increase in CRP levels. CRP levels have been associated with increased risk for cardiovascular pathology among other chronic inflammatory conditions such as arthritis, and there is evidence to support that overall inflammatory pathology in women is more common than in men (Appelman et. al., 2015). This effect may be due to dissociable influences of sex hormones, on inflammation (Schmidt et., 2006) and may suggest one possible reason why females show CRP levels at low arousal, that are comparable to males at high arousal. Duivis and colleagues (2013) found that somatic symptoms of patients with depression and anxiety were associated with CRP and IL-6. Additionally, they reported a sex-related interaction with CRP, such that, in males, higher cognitive symptoms of 
anxiety were associated with CRP levels (but not females). While our high arousal sample (MIDUS-2 $=169$ and MIDUS-R $=113$ ) was much smaller than the patient sample in their study ( $\mathrm{N}=2,231$ ), our findings are comparable, confirming the sensitivity of subjective arousal as a predictor of inflammation and of associated sex-related variability.

In the MIDUS-R sample, we additionally found elevated FIB levels in the high, relative to low arousal subgroup. After including covariates in the secondary model (Supplementary Results) the interaction of arousal and sex was significant for FIB in the MIDUS-2 sample. Males showed an arousal-related increase in FIB, while females showed no difference by arousal level and had comparable elevations to males at high and low arousal. In the MIDUS-R sample, this effect was consistent in direction, although not statistically significant. One reason for sex-related discrepancies between samples, may be that the high arousal group had a smaller sample size in MIDUS-R which may have reduced power to reliably detect small multiplicative effects. Fibrinogen is becoming increasingly relevant in the context of psychiatric disorders. For example, in a large sample of 73,367 patients, Wium-Anderson and colleagues (2013) found that individuals with higher plasma fibrinogen levels reported that they were more likely to give up, not accomplish tasks, use antidepressants, and were more likely to have a history of hospitalization for depression. Further, Martins-de-Souza and colleagues (2014), found that antidepressant responders versus non-responders had lower levels of fibrinogen alpha protein.

Causes of increased autonomic arousal and inflammation outside of aging and explicit disease/illness, include a wide range of psychosocial sources of stress. For example, low socioeconomic status, childhood adversity, loneliness, job loss, and caregiving responsibilities 
have all been linked to increases in stress-related autonomic activation and higher levels of inflammation (see Hänsel et al. 2010 for review). In both samples, females were over-represented in the high arousal subgroups, which is consistent with increased rates of mood and anxiety disorders among them. Furthermore, both high arousal subgroups reported lower household incomes, suggesting that economic stress may also be a factor in greater stress-related autonomic arousal and inflammation. Despite differences in age between our high arousal subgroups, and associations between age and proinflammatory activity (Michaud et al., 2013) these groups did not show a detectable difference in inflammatory markers, or significant interactions with age, however, larger sample sizes may be necessary in order to detect such potential differences. Our results also suggest that perceived control did not significantly predict or moderate inflammatory marker levels, which may seem contrary to the pathological stress model. However, prior work has illustrated that perceived control may activate adaptive immune pathways that alters the effect of chronic stress and inflammation but not necessarily the magnitude of basal proinflammatory activity (Koolhaas et al., 2011; Vogelzangs et al., 2016), suggesting perceived control may be impacting outcomes through a separable mechanism.

\section{Distinct Affective Symptom Patterns Across Subgroups}

Perceived control and subjective arousal also showed dissociable relationships with affective symptoms. Replicating across both samples, the high arousal and low control subgroup showed pathological elevations in depressive distress, anxious distress, and loss of interest relative to all other subgroups. The high arousal, high control subgroup showed less severe but still elevated symptoms of anxious distress and slight elevations in loss of interest in both samples. 
Both low control subgroups reported lower than average positive affect, consistent with prior work demonstrating a positive relationship between perceived control and levels of positive affect (Bogdan, Pringle, Goetz \& Pizzagalli, 2012; MacAulay, McGovern \& Cohen, 2014). In clinical samples, high symptoms of negative affect (depression and anxiety), are often (on average) correlated with symptoms of anhedonia or fatigue. In our study, the two low control subgroups both showed low positive affect even though the low arousal, low control subgroup did not show comparable elevations in loss of interest, depressive or anxious distress relative to the sample mean and did not have co-occurring elevations in pro-inflammatory markers. This suggests a potentially unique effect of low perceived control on limiting positive hedonic experiences, that is less dependent on pro-inflammatory mechanisms and stress. The lack of predictive relationship for perceived control on pro-inflammatory markers, and the unique effect of low perceived control on positive affect, offer further evidence regarding distinct mechanisms of action for perceived control and autonomic arousal as it relates to pathological affective outcomes, and inflammation.

One way in which perceived control may exert mental health-related benefits is through coping styles. For example, under conditions of high perceived control, stressors may increase motivation to engage in adaptive or healthy behaviors such as exercise or seeking social support. Conversely, those low in perceived control may be susceptible to coping efforts that sustain negative emotions when faced with stress or adversity (e.g. Burger, 1989), such as effortful avoidance or rumination (Lavender \& Watkins, 2004). Thus, control-linked styles of coping might be analogous to the long-standing distinction between problem and emotion-focused coping (Baker \& Berenbaum, 2003), the latter of which has been associated with inflammatory disease 
(Jones, Wessinger \& Crowell, 2005; Iglesias-Rey et al., 2012) as well as the general severity of physical illness (Endler, Kocovski \& Macrodimitris, 2001). Thus, future work evaluating the effects of personal control should also consider the potential moderating role of preferred coping strategies to further refine prediction of risk versus resilience toward the unfavorable health- and psychiatric-related consequences of stress and inflammation.

In terms of the associated neurobehavioral substrates of perceived control, Bhanji and Delgado (2014) found that greater persistence following controllable setbacks correlated with reduced activity in the ventral striatum. Notably, reduced striatal response following controllable setbacks did not correlate with negative affect ratings or the intensity of setbacks, but altered behavior in the context of stress. However, when participants were led to believe that outcomes were uncontrollable, change in ventromedial prefrontal cortex (vmPFC) activity to setbacks, mediated the relationship between negative affect post setback and persistence (greater positive change associated with greater persistence). An interesting observation is that striatal activity driving individual differences in persistence following controllable setbacks is orthogonal to negative affect. Likewise, in the uncontrollable case, the mediating role of greater vmPFC activity is again to reduce the association between negative affect and persistence (see Stolz, MüllerPinzler, Krach, \& Paulus, 2019) for related findings). This suggests that the relative protective effect of perceived control observed in our high-arousal, high control subgroup may act through a similar mechanism, by allowing individuals to attribute positive outcomes to their own actions, engage in goal-oriented cognitions, and to dissociate the experience of adverse events, from what they might mean for future action/outcomes. However future experimentation is necessary to test these hypotheses. 


\section{Limitations}

The cross-sectional design of this study has obvious limitations with respect drawing causal conclusions about the findings. At the same time cross-sectional designs are useful for identifying hypotheses that can be tested in experimental designs, and the current data allowed us to probe outcomes of chronic stress/adversity in humans that cannot be ethically and morally manipulated in a lab setting. Another limitation stems from lack of direct control over the specific variables available and the unequal subgroup sample sizes. For example, while fully stratifying our sample by age, sex, and race, especially in the smaller subgroups, may have revealed additional nuance, doing so would have limited the power and interpretability of our results. We nevertheless attempted to test the sensitivity of our effect by including relevant covariates in our models and found that most key findings remained significant. Finally, self-reported measures of affective symptoms across positive and negative domains often correlate. These domains are often also collinear with factor levels making them impossible to control statistically. Larger sample sizes that allow for stratification, or the use of other clinical comparison groups can improve our ability to dissociate these domains, if they are in fact dissociable. We attempted to address this potential issue of collinearity by choosing to separate individuals along hypothesized mechanistic dimensions of inflammation and affect rather than on the outcomes themselves (Elovainio et al., 2009; Dantzer et al., 2008).

\section{Conclusions and Future Directions}

The current study suggests that while measures of autonomic arousal may allow for adequate dissociation of individual differences in high versus low inflammatory outcomes, 
individual differences in perceived control at both high and low subjective arousal are crucial for dissociating heterogeneity in clinically relevant affective outcomes. This may be especially true for identifying individual differences in hedonic capacity both with and without co-occurring negative affect, making treatment decisions, and for better delineating resilient versus at-risk samples. One advantage of utilizing clustering approaches in large community and populationbased samples, such as the one reported here, is improved identification of naturally occurring variability as it relates to hypothesized mechanistic phenotypes of cognitive, affective, and behavioral outcomes. As observed here, some of this variability is at low prevalence relative to the majority of the population (e.g., $\mathrm{AA}+/ \mathrm{CNTL}+$ and $\mathrm{AA}+/ \mathrm{CNTL}$ - in the current study), which would inevitably mask effects at the total group level. Future work should extend findings from this study to experimentally or longitudinally test whether the phenotypic subgroups defined across arousal and perceived control dimensions in this study differ with respect behavioral or cognitive coping strategies, other health-related risks, or treatment response. 
Acknowledgments: M.G. would like to acknowledge Dr. Leslie Ungerleider and Dr. Shruti Japee for their support and guidance during the completion of this project. 


\section{References}

Acabchuk, R. L., Kamath, J., Salamone, J. D., \& Johnson, B. T. (2017). Stress and chronic illness : The inflammatory pathway. Social Science \& Medicine, 185, 166-170. https://doi.org/10.1016/j.socscimed.2017.04.039

Ambrée, O., Ruland, C., Scheu, S., Arolt, V., \& Alferink, J. (2018). Alterations of the innate immune system in susceptibility and resilience after social defeat stress. Frontiers in Behavioral Neuroscience, 12(July), 1-12. https://doi.org/10.3389/fnbeh.2018.00141

Appelman, Y., van Rijn, B. B., ten Haaf, M. E., Boersma, E., \& Peters, S. A. E. (2014). Sex differences in cardiovascular risk factors and disease prevention. Atherosclerosis, 241(1), 211-218. https://doi.org/10.1016/j.atherosclerosis.2015.01.027

Baker, J. P., \& Berenbaum, H. (2007). Emotional approach and problem-focused coping: A comparison of potentially adaptive strategies. Cognition and Emotion, 21(1), 95-118. https://doi.org/10.1080/02699930600562276

Bhanji, J. P., \& Delgado, M. R. (2014). Perceived control influences neural responses to setbacks and promotes persistence. Neuron, 83(6), 1369-1375.

https://doi.org/10.1016/j.neuron.2014.08.012

Bogdan, R., Pringle, P. L., Goetz, E. L., \& Pizzagalli, D. A. (2012). Perceived Stress, Anhedonia and Illusion of Control: Evidence for Two Mediational Models. Cognitive Therapy and Research, 36(6), 827-832. https://doi.org/10.1007/s10608-011-9413-8

Burger.J.M. (1989). Negative reactions to increases in perceived personal control. Journal of Personality and Social Psychology, 56(2), 246-256.

Chobanyan-Jürgens, K., \& Jordan, J. (2015). Autonomic nervous system activity and inflammation: good ideas, good treatments, or both? American Journal of Physiology-Heart and Circulatory Physiology, 309(12), H1999-H2001. https://doi.org/10.1152/ajpheart.00826.2015

Chue, P., \& Lalonde, J. K. (2014). Addressing the unmet needs of patients with persistent negative symptoms of schizophrenia: Emerging pharmacological treatment options. Neuropsychiatric Disease and Treatment, 10, 777-789. https://doi.org/10.2147/NDT.S43404

Ciavarra, R. P., Machida, M., Lundberg, P. S., Gauronskas, P., Wellman, L. L., Steel, C., ... Sanford, L. D. (2018). Controllable and uncontrollable stress differentially impact pathogenicity and survival in a mouse model of viral encephalitis. Journal of Neuroimmunology, 319(May), 130-141. https://doi.org/10.1016/j.jneuroim.2018.02.014 
Clark, L. A., \& Watson, D. (1991). Tripartite model of anxiety and depression: Psychometric eveidence and taxonomic implications. Journal of Abnormal Psychology, 100(3), 316-336. https://doi.org/10.1037/0021-843X.100.3.316

Craske, M. G., Meuret, A. E., Ritz, T., Treanor, M., \& Dour, H. J. (2016). Treatment for anhedonia: A neuroscience driven approach. Depression and Anxiety, 33, 927-938. https://doi.org/10.1017/CBO9781107415324.004

Dantzer, R., O’Connor, J. C., Freund, G. G., Johnson, R. W., \& Kelley, K. W. (2008). From inflammation to sickness and depression: When the immune system subjugates the brain. Nature Reviews Neuroscience. https://doi.org/10.1038/nrn2297

De Kloet, E. R., Joëls, M., \& Holsboer, F. (2005). Stress and the brain: From adaptation to disease. Nature Reviews Neuroscience. https://doi.org/10.1038/nrn1683

Dickerson, S. S., \& Kemeny, M. E. (2004). Acute stressors and cortisol responses: A theoretical integration and synthesis of laboratory research. Psychological Bulletin, 130(3), 355-391. https://doi.org/10.1037/0033-2909.130.3.355

Dijkstra, M. T. M., \& Homan, A. C. (2016). Engaging in rather than disengaging from stress: Effective coping and perceived control. Frontiers in Psychology, 7(SEP), 1-12. https://doi.org/10.3389/fpsyg.2016.01415

Duivis, H. E., Vogelzangs, N., Kupper, N., De Jonge, P., \& Penninx, B. W. J. H. (2013). Differential association of somatic and cognitive symptoms of depression and anxiety with inflammation: Findings from the netherlands study of depression and anxiety (NESDA). Psychoneuroendocrinology. https://doi.org/10.1016/j.psyneuen.2013.01.002

Dunn, B. D. (2012). Helping depressed clients reconnect to positive emotion experience: Current insights and future directions. Clinical Psychology \& Psychotherapy, 19(4), 326-340. https://doi.org/10.1002/cpp.1799

Elliot, A. J., Turiano, N. A., Infurna, F. J., Lachman, M. E., \& Chapman, B. P. (2018). Lifetime trauma, perceived control, and all-cause mortality: Results from the Midlife in the United States Study. Health Psychology, 37(3), 262-270. https://doi.org/10.1037/hea0000585

Elovainio, M., Aalto, A. M., Kivimäki, M., Pirkola, S., Sundvall, J., Lönnqvist, J., \& Reunanen, A. (2009). Depression and C-reactive protein: Population-based health 2000 study. Psychosomatic Medicine. https://doi.org/10.1097/PSY.0b013e31819e333a

Endler, N. S., Kocovski, N. L., \& Macrodimitris, S. D. (2001). Coping, efficacy, and perceived control in acute vs chronic illnesses. Personality and Individual Differences, 30(4), 617625. https://doi.org/10.1016/S0191-8869(00)00060-X 
Felger, J. C., \& Treadway, M. T. (2016). Inflammation Effects on Motivation and Motor Activity: Role of Dopamine. Neuropsychopharmacology: Official Publication of the American College of Neuropsychopharmacology. https://doi.org/10.1038/npp.2016.143

Foa, E. B., Zinbarg, R., \& Rothbaum, B. O. (1992). Uncontrollability and Unpredictability in Post-Traumatic Stress Disorder: An Animal Model. Psychological Bulletin, 112(2), 218 238. https://doi.org/10.1037/0033-2909.112.2.218

Fontaine, K. R., Manstead, A. S. R., \& Wagner, H. (1993). Optimism, perceived control over stress, and coping. European Journal of Personality, 7(4), 267-281. https://doi.org/10.1002/per.2410070407

Glaser, R., \& Kiecolt-Glaser, J. K. (2005). Stress-induced immune dysfunction: Implications for health. Nature Reviews Immunology. https://doi.org/10.1038/nri1571

Hänsel, A., Hong, S., Cámara, R. J. A., \& von Känel, R. (2010). Inflammation as a psychophysiological biomarker in chronic psychosocial stress. Neuroscience and Biobehavioral Reviews, 35(1), 115-121. https://doi.org/10.1016/j.neubiorev.2009.12.012

Hodes, G. E., Pfau, M. L., Leboeuf, M., Golden, S. A., Christoffel, D. J., Bregman, D., ... Russo, S. J. (2014). Individual differences in the peripheral immune system promote resilience versus susceptibility to social stress. Proceedings of the National Academy of Sciences, 111(45), 16136-16141. https://doi.org/10.1073/pnas.1415191111

Howren, M. B., Lamkin, D. M., \& Suls, J. (2009). Associations of depression with c-reactive protein, IL-1, and IL-6: A meta-analysis. Psychosomatic Medicine, 71(2), 171-186. https://doi.org/10.1097/PSY.0b013e3181907c1b

Jänig, W. (2014). Sympathetic nervous system and inflammation: A conceptual view. Autonomic Neuroscience: Basic and Clinical, 182, 4-14. https://doi.org/10.1016/j.autneu.2014.01.004

Jones, M. P., Wessinger, S., \& Crowell, M. D. (2006). Coping Strategies and Interpersonal Support in Patients With Irritable Bowel Syndrome and Inflammatory Bowel Disease. Clinical Gastroenterology and Hepatology, 4(4), 474-481. https://doi.org/10.1016/j.cgh.2005.12.012

Kaufman, L., \& Rousseeuw, P. J. (1990). Finding Groups in Data: An Introduction to Cluster Analysis (Wiley Series in Probability and Statistics). Eepe.Ethz.Ch. https://doi.org/10.1007/s13398-014-0173-7.2

Kerschensteiner, M., Gallmeier, E., Behrens, L., Leal, V. V., Misgeld, T., Klinkert, W. E. F., ... Hohlfeld, R. (1999). Activated human T cells, B cells, and monocytes produce brainderived neurotrophic factor in vitro and in inflammatory brain lesions: A neuroprotective role of inflammation? Journal of Experimental Medicine, 189(5), 865-870. https://doi.org/10.1084/jem.189.5.865 
Koolhaas, J. M. M., Bartolomucci, A., Buwalda, B., de Boer, S. F., Flügge, G., Korte, S. M. M., ... Fuchs, E. (2011). Stress revisited: A critical evaluation of the stress concept. Neuroscience \& Biobehavioral Reviews, 35(5), 1291-1301. https://doi.org/10.1016/j.neubiorev.2011.02.003

Kunz-Ebrecht, S. R., Mohamed-Ali, V., Feldman, P. J., Kirschbaum, C., \& Steptoe, A. (2003). Cortisol responses to mild psychological stress are inversely associated with proinflammatory cytokines. Brain, Behavior, and Immunity, 17(5), 373-383. https://doi.org/10.1016/S0889-1591(03)00029-1

Lachman, M. E., \& Weaver, S. L. (1998). The Sense of Control as a Moderator of Social Class Differences in Health and Well-Being, 74(3), 763-773.

Lavender, A., \& Watkins, E. (2004). Rumination and future thinking in depression. British Journal of Clinical Psychology, 43(2), 129-142.

https://doi.org/10.1348/014466504323088015

Lewitus, G. M., \& Schwartz, M. (2009). Behavioral immunization: Immunity to self-antigens contributes to psychological stress resilience. Molecular Psychiatry, 14(5), 532-536. https://doi.org/10.1038/mp.2008.103

MacAulay, R. K., McGovern, J. E., \& Cohen, A. S. (2014). Understanding Anhedonia: The Role of Perceived Control. In M. S. Ritsner (Ed.), Anhedonia: A Comprehensive Handbook Volume I (Vol. I, pp. 23-40). Springer. https://doi.org/10.1007/978-94-017-8610-2

Martins-De-Souza, D., Maccarrone, G., Ising, M., Kloiber, S., Lucae, S., Holsboer, F., \& Turck, C. W. (2014). Plasma fibrinogen: Now also an antidepressant response marker?

Translational Psychiatry, 4(1), e352-4. https://doi.org/10.1038/tp.2013.129

McEwen, B. S., \& Wingfield, J. C. (2003). The concept of allostasis in biology and biomedicine. Hormones and Behavior. https://doi.org/10.1016/S0018-506X(02)00024-7

Michaud, M., Balardy, L., Moulis, G., Gaudin, C., Peyrot, C., Vellas, B., ... Nourhashemi, F. (2013). Proinflammatory cytokines, aging, and age-related diseases. Journal of the American Medical Directors Association, 14(12), 877-882. https://doi.org/10.1016/j.jamda.2013.05.009

Michopoulos, V., \& Jovanovic, T. (2015). Chronic inflammation: A new therapeutic target for post-traumatic stress disorder? The Lancet Psychiatry. https://doi.org/10.1016/S22150366(15)00355-7

Miller, A. H., Haroon, E., Raison, C. L., \& Felger, J. C. (2013). Cytokine targets in the brain: Impact on neurotransmitters and neurocircuits. Depression and Anxiety, 30(4), 297-306. https://doi.org/10.1002/da.22084 
Miller, A. H., \& Raison, C. L. (2016). The role of inflammation in depression: From evolutionary imperative to modern treatment target. Nature Reviews Immunology, 16(1), 22-34. https://doi.org/10.1038/nri.2015.5

Miller, A. H., \& Raison, C. L. (2015). Are anti-inflammatory therapies viable treatments for psychiatric disorders? Where the rubber meets the road. JAMA Psychiatry, 72(6), 527-528. https://doi.org/10.1001/jamapsychiatry.2015.22

Miller, G. A., \& Chapman, J. P. (2001). Misunderstanding analysis of covariance. Journal of Abnormal Psychology. https://doi.org/10.1037/0021-843X.110.1.40

O’Donovan, A., Hughes, B. M., Slavich, G. M., Lynch, L., Cronin, M. T., O\&apos;Farrelly, C., \& Malone, K. M. (2010). Clinical anxiety, cortisol and interleukin-6: Evidence for specificity in emotion-biology relationships. Brain, Behavior, and Immunity, 24(7), 10741077. https://doi.org/10.1016/j.bbi.2010.03.003

Pongratz, G., \& Straub, R. H. (2014). The sympathetic nervous response in inflammation. Retrieved from http://arthritis-research.com/content/16/6/504

Scheller, J., Chalaris, A., Schmidt-Arras, D., \& Rose-John, S. (2011). The pro- and antiinflammatory properties of the cytokine interleukin-6. Biochimica et Biophysica Acta Molecular Cell Research, 1813(5), 878-888. https://doi.org/10.1016/j.bbamcr.2011.01.034

Schmidt, M., Naumann, H., Weidler, C., Schellenberg, M., Anders, S., \& Straub, R. H. (2006). Inflammation and sex hormone metabolism. Annals of the New York Academy of Sciences, 1069, 236-246. https://doi.org/10.1196/annals.1351.021

Schneider, B. A., Avivi-Reich, M., \& Mozuraitis, M. (2015). A cautionary note on the use of the Analysis of Covariance (ANCOVA) in classification designs with and without withinsubject factors. Frontiers in Psychology. https://doi.org/10.3389/fpsyg.2015.00474

Simons, R. L., Lei, M. K., Beach, S. R. H., Barr, A. B., Cutrona, C. E., Gibbons, F. X., \& Philibert, R. A. (2017). An index of the ratio of inflammatory to antiviral cell types mediates the effects of social adversity and age on chronic illness. Social Science and Medicine, 185, 158-165. https://doi.org/10.1016/j.socscimed.2017.03.005

Steptoe, A., Hamer, M., \& Chida, Y. (2007). The effects of acute psychological stress on circulating inflammatory factors in humans: A review and meta-analysis. Brain, Behavior, and Immunity. https://doi.org/10.1016/j.bbi.2007.03.011

Stolz, D. S., Müller-Pinzler, L., Krach, S., \& Paulus, F. M. (2019). The Pursuit of Pride: Outcomes Acheived Under Beliefs of Internal Control Shape Positive Affect and Neural Dyanamics in the vmPFC. BioRxiv, 637207. Retrieved from http://dx.doi.org/10.1101/637207 
Taylor, C. B. (2010). Depression, heart rate related variables and cardiovascular disease. International Journal of Psychophysiology. https://doi.org/10.1016/j.ijpsycho.2010.04.006

Vogelzangs, N., de Jonge, P., Smit, J. H., Bahn, S., \& Penninx, B. W. (2016). Cytokine production capacity in depression and anxiety. Translational Psychiatry, 6(5), e825. https://doi.org/10.1038/tp.2016.92

Wium-Andersen, M. K., Ørsted, D. D., \& Nordestgaard, B. G. (2013). Elevated plasma fibrinogen, psychological distress, antidepressant use, and hospitalization with depression: Two large population-based studies. Psychoneuroendocrinology, 38(5), 638-647. https://doi.org/10.1016/j.psyneuen.2012.08.006

Won, E., \& Kim, Y.-K. (2016). Stress, the Autonomic Nervous System, and the Immunekynurenine Pathway in the Etiology of Depression. Current Neuropharmacology, 14(7), 665-673. https://doi.org/10.2174/1570159X14666151208113006

Yang, C., Shirayama, Y., Zhang, J. C., Ren, Q., \& Hashimoto, K. (2015). Regional differences in brain-derived neurotrophic factor levels and dendritic spine density confer resilience to inescapable stress. International Journal of Neuropsychopharmacology, 18(7), 1-6. https://doi.org/10.1093/ijnp/pyu121 